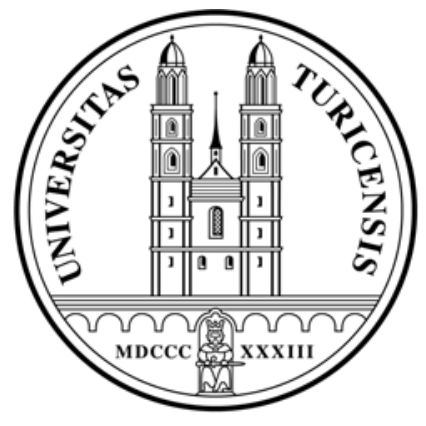

Institute for Empirical Research in Economics

University of Zurich

Working Paper Series

ISSN 1424-0459

Working Paper No. 449

Effects of Advertising and Product Placement on Television Audiences

Kenneth C. Wilbur, Michelle S. Goeree and Geert Ridder

September 2009 


\title{
Effects of Advertising and Product Placement on Television Audiences
}

\author{
Kenneth C. Wilbur ${ }^{1}$, Michelle S. Goeree ${ }^{2}$, and Geert Ridder ${ }^{3}$
}

January 4, 2009

\begin{abstract}
Digital video recorder proliferation and new commercial audience metrics are making television networks' revenues more sensitive to audience losses from advertising. There is currently limited understanding of how traditional advertising and product placement affect television audiences. We estimate a random coefficients logit model of viewing demand for television programs, wherein time given to advertising and product placement plays a role akin to the "price" of consuming a program. Our data include audience, advertising, and program characteristics from more than 10,000 network-hours of prime-time broadcast television from 2004 to 2007 . We find that the median effect of a $10 \%$ rise in advertising time is a $15 \%$ reduction in audience size. We find evidence that creative strategy and product category are important determinants of viewer response to advertising. When we control for program episode quality, we find that product placement time decreases viewer utility. In sum, our results imply that networks should give price discounts to those advertisers whose ads are most likely to retain viewers' interest throughout the commercial break.
\end{abstract}

Keywords: Advertising, Advertisement Avoidance, Branded Entertainment, Media, Product Placement, Television

\footnotetext{
${ }^{1}$ Asssistant Professor of Marketing, USC Marshall School of Business. kwilbur@usc.edu, http://wwwrcf.usc.edu/ kwilbur

${ }^{2}$ Professor of Economics, University of Zurich. mgoeree@iew.uzh.ch

${ }^{3}$ Professor of Economics, University of Southern California. ridder@usc.edu. http://www-rcf.usc.edu/ ridder/ We thank the Financial Economics Institute at Claremont McKenna College for financial support and Kevin Hesla for excellent research assistance.
} 
Television viewing is the dominant leisure activity in America. In a telephone survey Americans reported watching 2.6 hours of television per day, more than half of total leisure time. ${ }^{1}$ Other measures suggest time spent viewing is higher. Nielsen Media Research estimates the average adult watched 4.9 hours of television per day in $2007 .^{2}$

Television is still the dominant medium for audio/visual advertising. In 2007 the television industry earned $\$ 67.8$ billion in advertising revenues. Those revenues grew 35\% from 2001 to 2007 - more than twice as fast as inflation — and accounted for $48 \%$ of cumulative advertising expenditures. While some other advertising media (e.g., internet display advertising) grew at higher percentage rates due to smaller revenue bases, television advertising grew more than any other medium from 2001 to $2007 .^{3}$

Traditionally, broadcast television networks have provided viewers with nominally free programs in exchange for their attention and sold that attention to advertisers based on program audience measurements. The structure of the industry suggests that most viewers have a relative preference for programs or non-television activities over watching advertising. If this were not the case, networks would presumably refrain from producing such costly programming.

The traditional television business model has been weakened by two recent trends. First, viewers are acquiring digital video recorders (DVRs), which enable them to easily fast-forward past advertisements in recorded and "near-live" programming. The DVR was introduced in 1999, and $24.4 \%$ of American households owned one as of mid-2008. ${ }^{2}$ Figure 1 shows that broadcast networks have responded to DVR growth in part by increasing product placements ("unskippable advertising") in their shows by about 40\% in the three years to March 2008. Second, improvements in audience tracking technologies have changed business practices. Digital cable boxes and DVRs allow continuous tracking of channel tuning, leading advertisers to demand increasingly granular data about how many viewers watched a particular ad, rather than the program during which the ad appeared. Since September 2007, ad deals have been based on

\footnotetext{
${ }^{1}$ Source: Bureau of Labor Statistics, “American Time Use Survey," 2006.

${ }^{2}$ Source: Data reported online at www.tvb.org. Accessed November 2008.

${ }^{3}$ Source: TNS Media Intelligence custom report. In 2007 advertisers spent $\$ 28.0$ billion on magazines, $\$ 26.2$ billion on newspapers, $\$ 11.4$ billion on internet display advertising, $\$ 3.9$ billion on outdoor advertising, and $\$ 3.4$ billion on radio.
} 
programs' average commercial minute rating, ${ }^{4}$ rather than program rating. Many analysts expect more granular advertisement ratings to be available in the future.

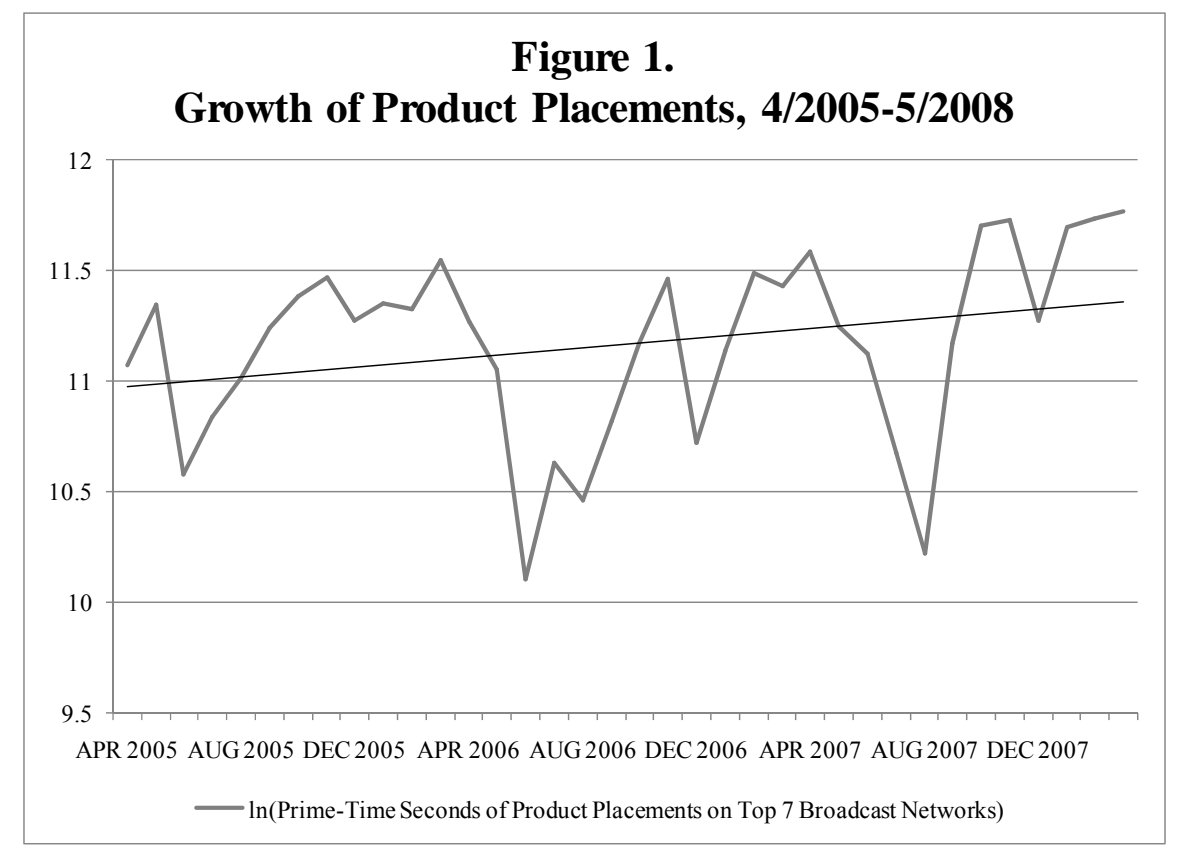

Thus viewers are better able to avoid advertisements than ever before. And networks are more likely to be financially penalized for advertisement avoidance than ever before. Our purpose in this paper, then, is to understand the effects of advertising and product placements on television audiences.

This understanding is important in practice for several reasons. First, it can inform networks' sales strategy, influencing which advertisers they seek to sell commercial time to. Second, it can influence networks' pricing. It may be optimal to raise ad prices for advertisers whose ads cause larger audience losses than average, or offer discounts to advertisers whose ads cause smaller audience losses. Third, viewer welfare is directly enhanced if networks can reduce viewer disutility from advertising. And if this reduction raises networks' advertising revenues, there may be an indirect effect on viewer welfare in the form of increased program investments.

\footnotetext{
${ }^{4}$ A commercial minute is any minute (e.g., 8:12:00 p.m.-8:12:59 p.m.) in which a part of a commercial is aired. The standard, called "C3," also includes DVR viewing up to 3 days after the program air date.

${ }^{6}$ We use the term "product placement" to refer to the inclusion of brands or products within television programs, also known as called "branded entertainment," "plugs," or "tie-ins." We refer to blocks of time sold to advertisers as "traditional advertising" or simply "advertising." We use the terms "program" and "show" interchangeably. An "ad creative" is a set of visual and audio stimuli encoded in a video file.
} 
We estimate a random coefficients logit model of television viewing demand using data from the television seasons ending in 2005, 2006, and 2007. In this model, the amount of time given to advertising and product placement is the "price" the viewer must pay to consume a program. We find that a $10 \%$ increase in advertising time causes a median audience loss of about $15 \%$. We find that the simple effect of product placement time on television audiences is positive, but when we control for program episode quality, we find that product placement time reduces audience sizes. Audience reaction to individual advertisements seems to be driven by advertising content and product category.

In section 1 we discuss salient features of the industry and the recent academic literature. We present our model of television viewing behavior in section 2 and discuss the data we use to estimate the model in section 3. We discuss the estimation strategy in section 4 . We present the results in section 5 and discuss their implications and limitations in section 6 . We confine most technical discussions (data issues, estimation, identification, etc.) to the technical appendix.

\section{Industry Background and Relevant Literature}

This paper is primarily related to three disparate strands of literature: advertisement avoidance, television viewing demand, and product placement. ${ }^{6}$

Several papers document the strategies television viewers use to avoid commercials. Danaher (1995) investigated Nielsen Peoplemeter ${ }^{7}$ data in New Zealand and found that audience sizes fell by a net $5 \%$ during ad breaks, due to a $10 \%$ audience loss to switching and a $5 \%$ audience gain from viewers leaving other channels. However, the context of the study was a three-channel environment in which simultaneous ad breaks were commonplace. Using Peoplemeter data from the Netherlands, Van Meurs (1998) found that channel switching decreased audience size during advertising breaks by a net $21.5 \%$. These finding are buttressed by the large literature on advertising wear-in and wear-out. For example, Siddarth and Chattopadhyay (1998) found the probability that a household switches channels during a particular ad is "J-shaped" with a minimum at 14 exposures.

Other researchers have measured advertisement avoidance in the lab. Woltman Elpers, et al. (2003) found that subjects stopped watching $59.6 \%$ and $76.1 \%$ of all commercials in two

\footnotetext{
${ }^{7}$ The peoplemeter is a box connected to television set. Each family member in a househould is assigned a viewing button on the peoplemeter that identifies the member's demographics.
} 
experiments. They found that commercial watching increases with entertainment content and decreases with information content. Teixeira, Wedel, and Pieters (2008) estimated the effects of commercial characteristics on commercial avoidance. Their findings include an inverted "U"shaped relationship between advertisement attention and visual complexity, and a positive effect of brand presence and duration on viewer switching. They used the estimates to calculate what pattern of brand appearances minimizes commercial avoidance, finding that, holding on-screen brand time constant, brand pulsing can reduce commercial avoidance substantially.

Advertising avoidance notwithstanding, until September 2007 advertising sales contracts were based on average program ratings, not advertisement ratings. Thus, the forms of advertising avoidance that most directly impacted network revenues were switching channels or turning off the television, as these are the two strategies most likely to decrease a program rating.

Quite separate from advertisement avoidance, there is a large literature on predicting viewer demand for television programs. Rust and Alpert (1984) were the first to use a discrete choice model to explain viewing behavior demonstrating that, contrary to previous findings, programs are important predictors of network audiences. More recently, Shachar and Emerson (2000) introduced cast demographic variables in viewing demand estimation and showed that viewers are more likely to watch programs that feature people who are demographically similar to themselves. Goettler and Shachar (2001) estimated a multidimensional ideal point demand system to calibrate a model of optimal program scheduling, finding that networks' adherence to scheduling heuristics (e.g. no situation comedies after 10 p.m.) was suboptimal. Anand and Shachar (2005) used data on viewers' exposure to television program "tune-ins" and subsequent viewing choices to identify tune-in effectiveness. They found that tune-ins are informative in nature: they make viewers more likely to watch programs that confer high subjective utility, and more likely to avoid programs that confer low subjective utility. Yang, Narayan, and Assael (2006) estimate a model in which husbands and wives have joint latent viewing preferences, finding that wives' viewing behavior depends more strongly on husbands' viewing status than vice versa.

A few studies have measured audience sensitivity to advertising levels, controlling for characteristics of media content. Wilbur (2008b) estimated indirect network effects on both sides of the television industry, finding that a highly-rated broadcast network loses about $25 \%$ of its median audience in response to a unilateral $10 \%$ increase in advertising time. Kaiser and Wright 
(2006) estimated a two-sided equilibrium model of viewers and advertisers of women's magazines, finding that ads increased reader utility from magazines. Depken and Wilson (2004) estimated magazine-specific audience responses to advertising and found substantial heterogeneity in preferences across magazines. The process by which advertising leads to increased or decreased viewership/readership has not been fully explored, but could depend on consumer demographics and heterogeneity, media content and usage, and advertising content, targeting, and intrusiveness. . Goeree (2008) found that advertising exposure and impact varies across demographic groups and advertising media, so it seems reasonable to expect that advertising avoidance also varies across consumer demographics and media.

We also study audience responses to product placement. The first on-screen product placement occurred shortly after the invention of the movie, when in 1896 the Lumiere brothers filmed women washing clothes with Lever Brothers' Sunlight Soap placed in a prominent position. Lever Brothers provided Swiss film distribution in exchange for the favorable treatment. A commonly cited successful placement was the appearance of Reese's Pieces in the film E.T. the Extraterrestrial, to which Hershey's attributed a 65\% rise in sales. Less commonly discussed is the placement of Coors Lite in the same film, to which no sales rise was attributed (Newell, Salmon and Chang 2006).

Balasubramanian, Karrh, and Parwardhan (2006) review the behavioral literature on product placement, attributing the many discrepancies among published findings to brand, consumer, and placement heterogeneity, and the difficulty of reproducing product placement stimuli in laboratory settings. An interesting framework is proposed by Russell (2002). She finds that placements have differential effects on consumers' memory and brand attitudes. Obtrusive placements are most likely to be remembered, but they positively influence consumers' attitude toward the brand only when they are congruent with the plot, and can harm brand attitudes when they are incongruent with the plot. These findings seem to refute Ephron's (2003) conjecture about product placement: "If you notice, it's bad. But if you don't, it's worthless."

Finally, there is a large recent theoretical literature on two-sided media markets. Prominent among these papers is Anderson and Coate (2005), which shows that television markets can fail by providing too many ads when available programs are poor substitutes, or too few when viewers are quick to switch and advertisers' profits are large relative to viewers' disutility of ads. Dukes and Gal-Or (2003) model both the market for advertising sales and its 
subsequent effects on a product market. They show that media outlets can benefit by selling exclusive advertising, since this softens product-market competition and raises advertisers' willingness to pay. Liu, Putler, and Weinberg (2004) show that networks' program investments may decrease with entry of additional networks. Our paper is relevant to this literature insofar as our results inform the assumptions it makes about how viewers respond to advertising of various types. The literature is reviewed by Anderson and Gabszewicz (2006).

Our contributions to knowledge about audience reactions to advertising and product placement are as follows. We examine several functional forms and find the magnitude of these effects contradict some recently published evidence. We estimate these effects using a dataset that is about 25 times larger (in terms of programs and time periods) than any studied previously. We generate important new findings about what advertisement characteristics influence audience responsiveness to advertising; this knowledge should be actionable to policymakers and managers in a variety of industries. To our knowledge, our study is the first to estimate the effect of product placements on viewer switching using field data. Our findings have implications for how laboratory studies of product placement should be designed. Taken as a whole, our results have important implications for television networks' business models and consequently viewers' leisure time and marketers' advertising expenditures.

\section{A Model of Television Viewing Behavior}

In this section we describe our model of television viewing demand. We follow previous literature by assuming that each television viewer watches one network at a time, and model program viewership in a discrete choice framework. Given the aggregate nature of our data, we use a random coefficients logit model in the spirit of Berry, Levinsohn, and Pakes (1995 and Nevo (2001). We include the essential details in the body of the paper and refer interested readers to the technical appendix for discussions of methodological issues.

Traditionally, a rating is the fraction of all potential viewers who watched a given program. A share is the fraction of all viewers watching television who watched a given program. Our data measure program ratings, so we use this terminology throughout the paper. Similarly, we use the term "product placement" to refer to the inclusion of brands or products within television programs, which is sometimes called "branded entertainment," "plugs," or "tieins." We refer to blocks of time sold to advertisers as "traditional advertising" or simply 
"advertising." We use the terms "program" and "show" interchangeably. Finally, an "ad creative" is a set of visual and audio stimuli encoded in a video file.

We index networks with $n$ and programs with $j$. A viewer chooses from $n=1 \ldots N_{t}$ networks airing top-100 programs within half hour $t^{8}{ }^{8}$ There exists a one-to-one mapping from network-half hours $(n t)$ to program-half hours $(j t){ }^{9}$

Viewer utility is determined by time effects, program and network characteristics, advertising and product placement, and preference parameters. The indirect utility viewer $i$ derives from watching network $n$ in half hour $t$ is given by

$$
u_{\text {int }}=v\left(p_{n t}, q_{n t} ; \alpha_{i}\right)+X_{n t} \beta_{i}+\xi_{n t}+\varepsilon_{\text {int }}
$$

where $p_{n t}$ is the number of seconds of product placements on network $n$ during half-hour $t, q_{n t}$ is the number of seconds of traditional advertising on network $n$ during half-hour $t, \alpha_{i}$ is a vector of utility parameters, and $v\left(p_{n t}, q_{n t} ; \alpha_{i}\right)$ is the utility obtained from advertising and product placement. In section 5, we report results for several specifications of $v\left(p_{n t}, q_{n t} ; \alpha_{i}\right)$.

The $X_{n t}$ vector contains program, network, and time data. These include program dummies that capture the program characteristics (genre etc), a dummy for whether the airing was a new episode; network-day dummies, to capture networks' historical schedule strengths and weaknesses; half-hour effects, to allow television utility to vary over the course of the night; and season-week dummies, to allow the utility of watching television to vary over weeks and years. Many previous studies (e.g., Moshkin and Shachar 2002) demonstrate the importance of state dependence in television viewing, so we also include the network's audience rating for the same weekday-half hour in each of the previous five weeks. ${ }^{10}$

In entertainment categories like television shows, observed product characteristics are often inadequate to capture product quality.. The $\xi_{n t}$ term represents time-changing characteristics of the program that are unobserved to the researcher but known by viewers, advertisers, and networks. Note that the time-constant component is captured by the program

\footnotetext{
${ }^{8}$ Our audience datasource is a set of weekly "top 100" programs, described further in section 3.

${ }^{9}$ We could alternatively think of a consumer choosing a program-half hour combination. To be consistent with previous literature we model the viewer's decision as choosing a network-half hour.

${ }^{10}$ Many programs are serial in nature, so previous weeks' ratings are likely to predict demand for the current program.
} 
dummies, so that the $\xi_{n t}$ reflect variation in episode quality.

Equation 2 defines the distribution of the random utility parameters.

$$
\left(\begin{array}{c}
\alpha_{i} \\
\beta_{i}
\end{array}\right)=\left(\begin{array}{l}
\alpha \\
\beta
\end{array}\right)+\Phi v_{i}, \quad v_{i} \sim N\left(0, I_{K}\right)
$$

$v_{i}$ represents viewer tastes that are not observed by the econometrician and is a $K$-dimensional vector drawn from a multivariate standard normal distribution. We assume that the $v_{i}$ are independently normally distributed across the population with mean zero and variance 1 . The $\Phi$ term is a diagonal $\mathrm{KxK}$ scaling matrix of parameters (the standard deviations of the random coefficients) to be estimated. ${ }^{11} \mathrm{We}$ assume that the $v_{i}$ are independent of $\varepsilon_{\text {int }}$.

The number of parameters $K$ can be as large as the combined dimensions of $\alpha_{i}$ and $\beta_{i}$, but is typically chosen to be smaller, as estimation time increases exponentially in $K$. We could include individual demographics drawn from population-level distributions in Equation (2), but given that we do not have meaningful variation in viewer demographics over markets or time, it is not clear that these effects would be separately identified from $\Phi$. However, as we discuss in section 5, we estimate a restricted model separately for each demographic group in our data and hence our parameter estimates vary over demographic groups.

The $\varepsilon_{\text {int }}$ is distributed i.i.d. type I extreme value across viewers, networks, and time periods. If we restrict the elements of $\Phi$ to zero, we have specified a multinomial logit model. We can rewrite equation 1 as (all specifications of $v\left(p_{n t}, q_{n t} ; \alpha_{i}\right)$ are linear in the random coefficient)

$$
u_{\text {int }}=\delta_{n t}+\mu_{\text {int }}+\varepsilon_{\text {int }}
$$

where $\delta_{n t}=v\left(p_{n t}, q_{n t} ; \alpha\right)+X_{n t} \beta+\xi_{n t}$ captures the base utility every viewer derives from network $n$ at time $t$. The composite random shock, $\mu_{\text {int }}+\varepsilon_{\text {int }}$, captures viewer preference heterogeneity.

Viewers may elect to watch a a program outside the top 100, a cable network, or engage in a non-television activity. The value of the best available alternative (the "outside option") is given by

\footnotetext{
${ }^{11}$ Including random coefficients ensures that predicted switching patterns will be based on similarity in observed characteristics, rather than based solely on similarity in audience ratings.
} 


$$
u_{i 0 t}=\xi_{0 t}+\varepsilon_{i 0 t}
$$

Given that we cannot identify relative utility levels, we normalize $\xi_{0 t}$ to zero. The conditional probability that viewer $i$ watches network $n$ at time $t$ is

$$
S_{i n t}=\frac{e^{\delta_{n t}+\mu_{i n t}}}{1+\sum_{l}^{N_{t}} e^{\delta_{l t}+\mu_{i l t}}}
$$

The audience rating for network $n$ at time $t$ is

$$
s_{n t}=\int_{A_{n t}} s_{i n t} d F(v)
$$

where $F(v)$ denotes the cumulative distribution function of $v$, which is assumed to be independent of the logit error term. Notice that network $n$ 's audience rating is a function of network and program characteristics and advertising for all programs.

\section{Data}

To estimate the model we use data from two sources: TNS Media Intelligence (TNS) and the Television Bureau of Advertising (TVB). The TNS data are extensive and contain program genre classifications, detailed advertising data at the level of the individual ad placement, and detailed product placement data at the level of the individual product placement. The TVB data report television audience ratings at the date-network-program level for the top 100 national programs that aired during prime time evening hours each week (8-11 P.M.) during which networks earn $61 \%$ of their advertising revenues.

Since programs typically change on half-hour increments, our unit of observation is the date-network-half-hour, e.g. January 1, 2007, ABC, 8:00-8:30 P.M. We discuss each component of the data in more detail, and present descriptive statistics in section 3.5.

\subsection{Program Data}

Program characteristics data come from TNS and consist of program name, genre, network, and date of each airing. We observe each advertisement within each program, so we are able to construct start and end times for each program-date. 
The networks in the data are ABC, CBS, CW, FOX, NBC, UPN, and WB. ${ }^{12}$ FOX broadcasted national programs 8-10 on all seven nights (all times are P.M., Eastern Standard Time). UPN broadcasted 8-10 Monday through Friday, and WB broadcasted 8-10 Sunday through Friday. WB and UPN merged and began broadcasting as the CW Network in September 2006. CW broadcasted 8-10 Sunday through Friday in the 2006-07 season.

TNS assigns each program to a genre. Numerous studies (e.g. Rust and Alpert 1984, Goettler and Shachar 2001) illustrate the importance of program genre in predicting program viewing demand. Table 1 lists the genres ordered by the frequency of the network-half-hours in which they are programmed in the sample. Genres range from News Magazine to Wrestling. But the striking feature of the data is its relative lack of dispersion. Four genres-Drama/Adventure, Slice-of-Life, Situation Comedy, and Police/Suspense/Mystery-accounted for $76.4 \%$ of primetime network program-hours. At the other end of the distribution, 30 genres account for just $7.02 \%$.

Genre
Drama/Adventure
Slice-of-Life (or "Reality")
Situation Comedy
Police/Suspense/Mystery
Feature Film
News Magazine
Wrestling

Frequency
$1.66 \%$
$1.14 \%$
$1.04 \%$
$0.99 \%$
$0.98 \%$
$0.55 \%$
$4.51 \%$

Table 1. Genre Frequency

\subsection{Advertising Data}

We use advertising data from TNS Media Intelligence's "Stradegy" database. This database provides advertisers, advertising agencies, and other marketers with "competitive advertising intelligence." It is widely subscribed within the industry.

For all advertisements that aired during the sample period, we observe the brand advertised (e.g. Coca-Cola Classic), the network, start time, and length of the ad, and a name

\footnotetext{
${ }^{12}$ FOX started a new network called My Network Television in 2006, but none of its program audiences were large enough to be included in our sample.
} 
given to the ad creative. In addition, TNS manually classified each brand as belonging to a category (e.g. Regular Carbonated Soft Drinks), an industry (Beverages), a subsidiary (CocaCola USA) and a parent company (Coca-Cola Co.).

Networks aired about 250,000 advertisements during our sample period. These included about 29,000 different ad creatives for 5,000 brands spanning 350 categories in 50 industries.

We have data on the average price of a 30 -second commercial for each program on each date. Networks report these date-program average advertising costs to TNS and Nielsen after their programs air. These data allow media buyers to estimate costs of future media plans. If networks over-report these costs, they have a greater ability to give advertisers perceived discounts when negotiating ad prices, but they may limit their programs' potential advertising demand. We are not aware of any evidence of systematic under- or over-reporting, perhaps because of the repeated nature of transactions in this industry. (These are not "rate card" data.)

\subsection{Product Placement Data}

TNS Media Intelligence began recording product placement information on March 28, 2005. In their database, a product placement is a visual, audio, or audio-visual representation of a brand or product, whether explicit or implied. Common examples include detailed prize descriptions on a game show, a logo on the t-shirt of a reality show contestant, or a partially identifiable truck driven by a police officer in a dramatic series.

For each product placement, we observe the brand placed, the brand characteristics defined above, and the product placement characteristics listed in Table 2. In the median placement, an identifiable product or package is shown in the foreground with no other brands or products on the screen. Products are integrated into the program's plot in just $16 \%$ of all placements. As with advertising, we aggregate over placements to construct measures of product placement at the date-network-half-hour level.

Networks typically do not reveal placement terms, so no available datasource reports product placement prices. Our understanding of the industry is that product placements are sometimes paid in cash, sometimes bartered, and sometimes are not paid. Payment is more likely when plot integration or character interaction occurs, in which case the integration or interaction almost always depicts the brand or product favorably and/or prominently. 
In the product placement data, we observe episode names for regular programs.

Therefore, for the second and third television seasons in our data, we were able to construct an

\begin{tabular}{|c|c|c|c|c|}
\hline & Variable & & & Notes \\
\hline \multirow[t]{5}{*}{ Type } & Verbal Only & & $17.0 \%$ & \\
\hline & Direct Visual Only & & $51.2 \%$ & Brand/product is clearly identifiable \\
\hline & Implied Visual Only & & $24.5 \%$ & Brand/product is not clearly identifiable \\
\hline & Verbal \& Direct Visual & & $5.3 \%$ & \\
\hline & Verbal \& Implied Visual & & $2.0 \%$ & \\
\hline \multirow[t]{5}{*}{ Appearance } & Product or Package shown & & $63.9 \%$ & \\
\hline & Brand Name shown & & $11.4 \%$ & \\
\hline & Brand Mark shown & & $4.6 \%$ & \\
\hline & Billboard or Graphic Overlay & & $3.1 \%$ & \\
\hline & No Visual & & $17.0 \%$ & \\
\hline \multirow[t]{3}{*}{ Interaction } & Interaction w/ Real Life Persona & & $21.6 \%$ & \\
\hline & Interaction w/ Fictional Character & & $37.4 \%$ & \\
\hline & No Interaction & & $41.0 \%$ & \\
\hline$\overline{\text { Visual }}$ & Brand Interaction & & $7.9 \%$ & E.g. a character wears a shirt with a Nike logo \\
\hline Interaction & Product Interaction (Proper Use) & & $33.2 \%$ & \\
\hline \multirow[t]{2}{*}{ Type } & Product Interaction (Improper Use) & & $1.0 \%$ & \\
\hline & No Interaction & & $57.8 \%$ & \\
\hline \multirow[t]{6}{*}{ Integration } & Integration as a Prize or Reward & & $1.3 \%$ & $\begin{array}{l}\text { Characters who successfully completed a game or contest were } \\
\text { given the brand as a reward }\end{array}$ \\
\hline & Integrated Directly into Game/Contest & & $2.8 \%$ & The brand/product was featured during the game/contest \\
\hline & Integrated Partially Into Game/Contes & & $1.3 \%$ & The brand/product was used during the game/contest \\
\hline & Integration as a Sponsorship & & $8.2 \%$ & The brand was presented as a sponsor of the program \\
\hline & Other Integration & & $2.6 \%$ & E.g. the brand was integrated with the plot of a dramatic program \\
\hline & No Integration & & $83.9 \%$ & \\
\hline \multirow[t]{3}{*}{ Visibility } & Fully Visible & & $39.8 \%$ & \\
\hline & Partially Visible & & $40.6 \%$ & \\
\hline & Not Applicable & & $19.6 \%$ & \\
\hline \multirow[t]{3}{*}{ Clutter } & No Clutter & & $58.1 \%$ & \\
\hline & Clutter & & $24.9 \%$ & $\begin{array}{l}\text { At least } 1 \text { other brand/product appeared on screen during a visual } \\
\text { product placement }\end{array}$ \\
\hline & Not Applicable & & $17.0 \%$ & \\
\hline $\begin{array}{l}\text { Visual } \\
\end{array}$ & Foreground & & $60.7 \%$ & \\
\hline \multirow[t]{2}{*}{ Location } & Background & & $22.2 \%$ & \\
\hline & Not Applicable & & $17.0 \%$ & \\
\hline \multirow[t]{4}{*}{ Length } & in Seconds & Mean & 23.4 & \\
\hline & & Med. & 9.0 & \\
\hline & & St.D. & 42.3 & \\
\hline & & $\operatorname{Max}$ & 920.0 & \\
\hline
\end{tabular}

Table 2. Product Placement Descriptive Statistics.

indicator of whether each episode had appeared previously in the television season. ${ }^{13}$ We call this variable NewEps. It stands to reason that new program episodes are more attractive to

\footnotetext{
${ }^{13}$ We were not able to observe this for the first season since the product placement data sample did not begin until March 2005.
} 
viewers than previously-aired episodes ("re-runs"), so we use this information in predicting viewing demand.

\subsection{Television Audience Data}

Only a handful of television audience datasets have been available to academic researchers in the past 20 years. Most of those contain individual viewers' program choices over a limited number of days and programs. Our data contrast with others in that we have an unusually large number of time periods and programs, but we do not have cross-sectional variation over individuals or markets.

We collected our audience data from weekly "top 100" program lists found on the TVB website (tvb.org). Each list ordered the 100 highest-rated programs that week and included the programs' national audiences, as measured by Nielsen Media Research.

The audience measurements are collected in the following way. Television usage and tuning in a geographically representative sample of approximately 9,000 households are monitored continuously using Peoplemeters. Viewers in those households are prompted to "log in" every 20-40 minutes they watch television; the log-in data are used to construct the demographic ratings. The Peoplemeter records viewing for each viewer that is "logged in" for each network in each second of each minute of the day. The program audience ratings are then constructed as averages over the network-day-minute-seconds in which that program aired. For example, if a viewer in the Nielsen sample watches NBC from 8-8:20 and then watches ABC from 8:20-8:30, that viewer accounts for "two-thirds" of a viewer for NBC in the 8-8:30 half hour, and "one-third" of a viewer for $\mathrm{ABC}$ from 8-8:30.

Weekly top-100 program lists were available for three demographic groups in each of three 35-week television "seasons," 2004-05, 2005-06, and 2006-07. Each season began on the third Monday of September and ended on the third Sunday in May. The demographic groups are those traditionally used to measure television audiences: adults aged 18-49, adults aged 25-54, and households. The unit of observation is a date-network-program, so we assign each datenetwork-program rating to the network-half-hour in which that program aired. 


\subsection{Descriptive Statistics}

Table 3 displays advertising and audience descriptive statistics by network. CBS had the largest audience measured in households, by far, with an average rating of 8.24 , followed by $\mathrm{ABC}$ (6.55) and NBC (6.33). Yet FOX led in advertisers' most desired demographic, adults 18-49 (4.15), followed by CBS (3.93) and ABC (3.77). This lead in adults 18-49 yielded Fox's premier position in advertising revenues per half hour.

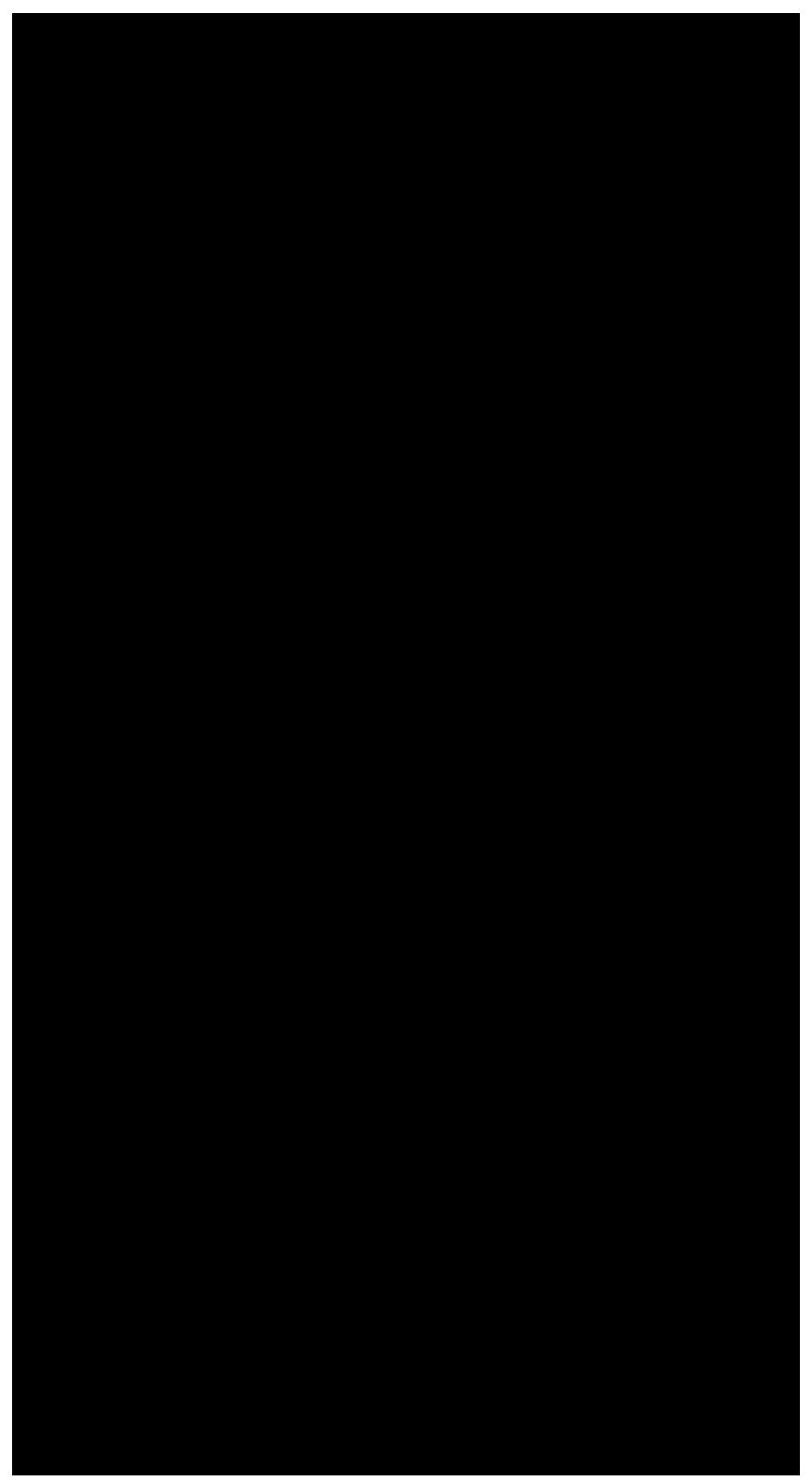

Table 3. Descriptive Statistics 
WB and UPN had audiences and advertising revenues about half as large as the big four networks. It is surprising to compare the CW network's performance to WB and UPN. CW had smaller audiences than either of its constituent networks, and lower average advertising revenues than UPN. It would appear that the WB-UPN merger was unprofitable, unless it produced substantial unobserved program cost savings.

ABC carried the highest advertising loads in the sample, with an average of 370 seconds of ads per half-hour. It was followed by WB (349), CW (340), UPN (334), NBC (318), CBS (309), and FOX (296). There was a great deal of dispersion around these means, with standard deviations about $25 \%$ as large as means of advertising time. ${ }^{14}$ Figure 2 shows histograms of ad seconds by network. It appears that networks followed somewhat different strategies in setting ad levels. For example, ABC had substantially more dispersion in ad time than FOX or UPN. CBS' distribution of ad seconds takes a sharp jump at 180. And CW's distribution of advertising time is bimodal at about 270 and 360 .

14 There were 1320 seconds (22 minutes) of advertising on CBS during the NFL Pre-Game Kickoff Show from 8:00-8:30pm EST on December 10, 2006. 
Histogram of ABC Ad Seconds

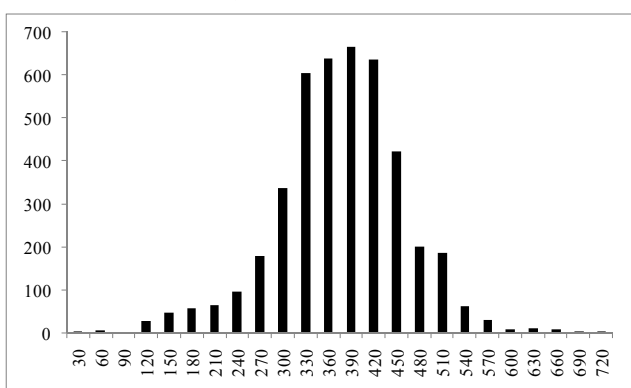

Histogram of CW Ad Seconds

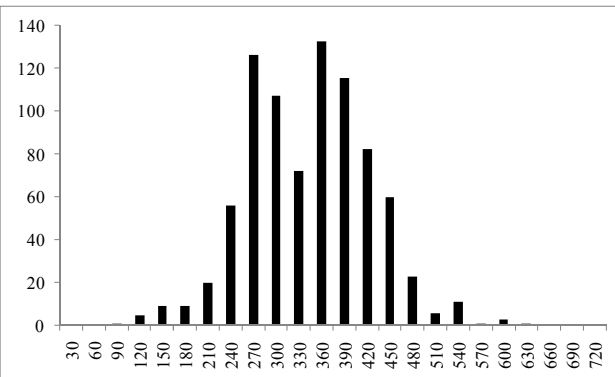

Histogram of NBC Ad Seconds

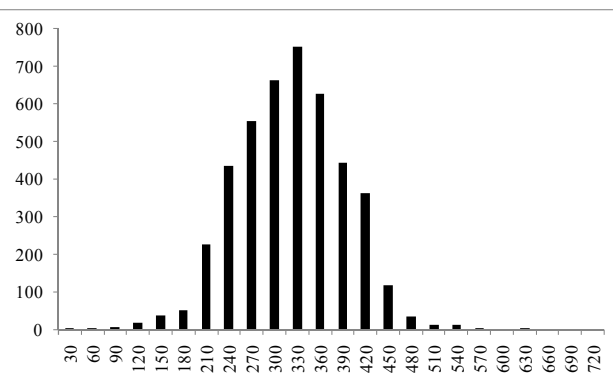

Histogram of WB Ad Seconds

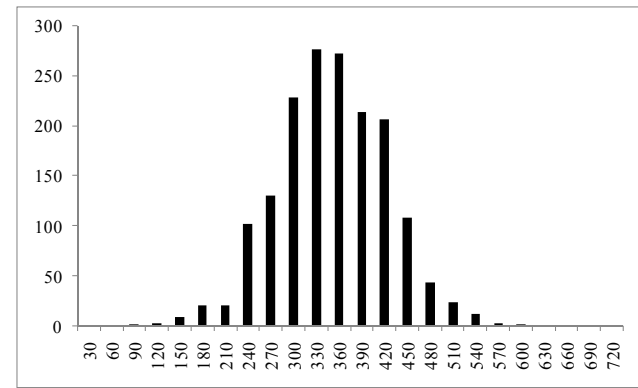

Histogram of CBS Ad Seconds

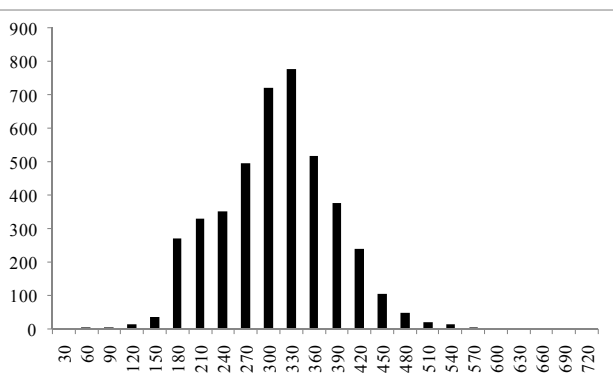

Histogram of FOX Ad Seconds

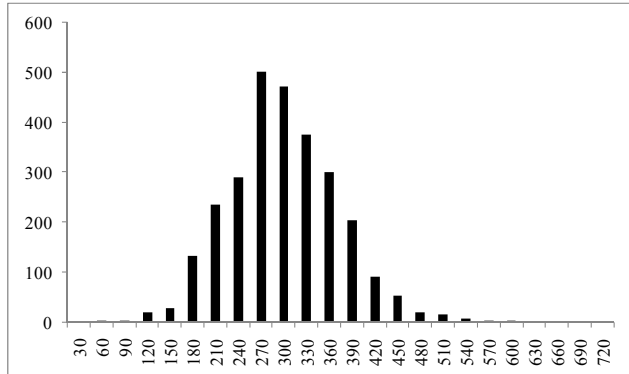

Histogram of UPN Ad Seconds

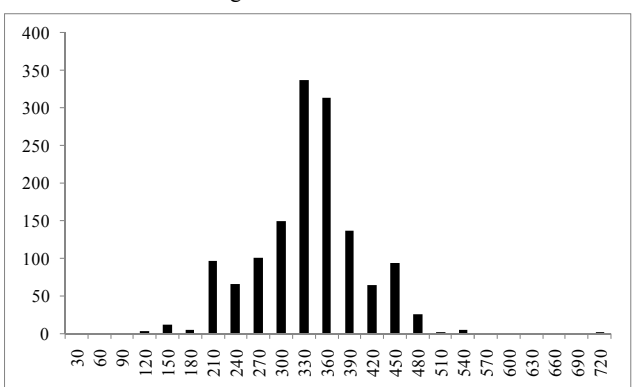

Figure 2. Histograms of Ad Seconds by Network

While FOX had the lowest advertising quantities, it carried the most product placement, with an average of 141 seconds per prime-time half-hour. This was followed by NBC (129), UPN (127), CBS (110), CW (85), WB (69) and ABC (43). Product placement time is skewed heavily toward the origin with $46 \%$ of network-half hours containing no product placements at 
all. Product placements can overlap (multiple placements can be on the screen at once), leading to high maximal levels of product placement in a few cases.

Table 4 shows the raw correlations between the major variables. Notably, the correlation between advertising and product placement is close to zero. It is also notable that product placement time is positively correlated with audience ratings, with correlations ranging from 0.13 to 0.17 .

$\begin{array}{lrrrrrr} & \text { Ad Sec. } & \text { PP Sec. Ad Doll. } & \text { HH } & \text { A18-49 } & \text { A25-54 } \\ \text { Ad Seconds } & 1.00 & & & & & \\ \text { Product Placement Seconds } & -0.04 & 1.00 & & & & \\ \text { Ad Dollars } & 0.33 & 0.12 & 1.00 & & & \\ \text { Household Rating } & 0.02 & 0.13 & 0.66 & 1.00 & & \\ \text { Adults 18-49 Rating } & 0.05 & 0.17 & 0.72 & 0.92 & 1.00 & \\ \text { Adults 25-54 Rating } & 0.04 & 0.16 & 0.70 & 0.96 & 0.99 & 1.00 \\ \text { Drama/Adventure } & 0.02 & -0.05 & -0.03 & 0.02 & 0.02 & 0.04 \\ \text { Police/Suspense/Mystery } & -0.10 & -0.08 & 0.02 & 0.18 & 0.07 & 0.11 \\ \text { Situation Comedy } & 0.06 & 0.04 & -0.04 & -0.18 & -0.11 & -0.13 \\ \text { Slice-of-Life ("Reality") } & 0.03 & 0.30 & 0.08 & 0.05 & 0.14 & 0.10\end{array}$

Table 4. Correlations among Key Variables

Slice-of-Life and Situation Comedy programs contain more advertising and product placement time than Drama/Adventure and Police/Suspense/Mystery programs. While audiences across demographic groups are highly correlated, genre preferences depend on demographics. Household-level audiences are more likely to watch police programs than adults $18-49(0.18$ correlation to 0.07 ), while adults $18-49$ are more likely to watch reality programs than the households audience (0.14 to 0.05$)$.

\section{Estimation}

In this section we discuss potential endogeneity issues and how we address them and the estimation technique. We discussion identification and more details in the technical appendix.

\subsection{Endogeneity}

The error term in the model is $\xi_{n t}$, which represents program characteristics that may be known to the networks and viewers but are unobserved by the econometrician. We specify

$$
\xi_{n t}=\xi_{j}+\Delta \xi_{n t}
$$


where $\xi_{j}$ is the mean of unobserved characteristics for program $j$, and the $\Delta \xi_{n t}$ term represents deviations from this mean over time periods in which the program airs. (Recall that there is a one-to-one mapping from $n t$ into $j t$, so we could equivalently write $\Delta \xi_{j t}$ in place of $\Delta \xi_{n t}$.) We use the serial nature of the data to estimate $\xi_{j}$ by including program-specific fixed effects. The $\Delta \xi_{n t}$ could capture unobserved temporal variation in program quality as some episodes of a program may be more entertaining than others. It could also capture variation in time given to tune-ins. To address this, we include ad price per viewer and its lags in the viewer utility function as this variable is likely to be correlated with tune-in seconds. ${ }^{15}$ We include NewEps, network-weekday and season-week dummies in $X_{n t}$ to try to reduce variation in $\Delta \xi_{n t}$ due to episode quality, networks' historical schedule strength, and temporally variable factors like weather.

Television networks may know their programs' and episodes' quality, including those aspects captured in $\Delta \xi_{n t}$, and may take it into account when setting traditional advertising and product placement levels. As a result we have a potential endogeneity problem in that advertising choices may be functions of $\Delta \xi_{n t}$.

We use three sets of instruments to address potential remaining endogeneity issues: (1) lags of traditional advertising time, (2) lags of product placement time, and (3) functions of competitors' program characteristics. Regarding the first two sets of instruments, traditional advertising time and product placement seconds are autocorrelated (1-week correlations of 0.42 and 0.44 , respectively), so lags are good proxies for current advertising time and product placements. Their exclusion from the viewer utility function is justified if networks are myopic when setting traditional advertising time and product placements. ${ }^{16}$ The intuition motivating the third set of instruments follows Goeree (2008) and is similar to that used by BLP to correct for endogeneity of price in differentiated products markets. Rivals' program characteristics enter the network's profit function and therefore influence the network's choice of ad and product placement time, since the optimal amount of advertising to do on a program depends upon the characteristics of all of the programs aired by rivals. Hence, characteristics of rivals' programs

\footnotetext{
${ }^{15}$ We originally treated ad price per viewer as an instrument, but instrumental variables validity tests reported in Appendix 1 indicated that their exclusion from viewer utility was not justified.

${ }^{16}$ Our approach is analogous to Villa-Boas and Winer (1999) who show that lagged variables are valid instruments in this setting. We also include program fixed effects.
} 
and various combinations of these characteristics can be used to instrument for endogenous advertising in that they are correlated with advertising aired during program $j$ but not with program $j$ 's unobserved quality. These instruments are given by $g_{n t}$, where $g$ is the number of competing networks offering a program with characteristic $g$ within date/half-hour $t$. The characteristics $g$ that we consider are NewEps and genre effects. Finally, for validity of these instruments and to identify the taste parameters (discussed in the next section), we assume (as in BLP and Nevo, 2000) that the observed and unobserved program characteristics are mean independent. $^{17}$

\subsection{Estimation}

The econometric technique follows recent studies of differentiated products, such as BLP (1995) and Nevo (2000). We estimate the model using the Generalized Method of Moments (GMM). The moments match the predicted demographic audience ratings for network-half hours $n t$ to the corresponding observed ratings.

Following the literature, we assume that the demand unobservables (evaluated at the true parameter values) are mean independent of a set of exogenous instruments, $z$. To estimate the restricted model we follow Berry (1994). Setting $\Phi=0_{K}$, the model in section 2 reduces to a multinomial logit with an ordinary least squares (OLS) estimating equation of

$$
\ln s_{n t}-\ln s_{0 t}=\delta_{n t}=v\left(q_{n t}, p_{n t} ; \alpha\right)+X_{n t} \beta+\xi_{j}+\Delta \xi_{n t}
$$

where $s_{0 t}$ is the audience rating of the outside good (one minus the sum of the "inside" shares). To estimate the parameters we interact the error term $\Delta \xi_{n t}$ with a set of variables, $Z$. In our first set of regressions, $Z$ includes all the right-hand side variables, i.e. program dummies, seasonweek dummies, network-weekday dummies, half-hour dummies, genre dummies, NewEps, five (weekly) lags of audience share and ad price per viewer, product placement characteristics, and the observed data in $v\left(p_{n t}, q_{n t} ; \alpha\right)$. In the instrumental variables (IV) specifications, we add five lags of traditional advertising time and five lags of product placement time into $Z$ and exclude advertising and product placement time that are potentially endogenous

\footnotetext{
${ }^{17}$ Given that we observe variation in the programs offered in different time slots, these instruments are valid even though we estimate program fixed effects.
} 
To estimate the full set of random coefficients, we add the competitors' program characteristics described above to $Z$ along with the lags of advertising and product placement time, and adopt the two-step estimator proposed by BLP. See the technical appendix for details.

\section{Results}

In sections 5.1-5.3 we present estimates from several specifications of the multinomial logit (MNL) model without random coefficients. The ease of MNL estimation makes it helpful for specification testing and computing estimates for models with large numbers of parameters. However, its assumption of preference homogeneity implies that its counterfactual predictions will be affected by the well-known independence of irrelevant alternatives property. We therefore use the random coefficient logit model to estimate how audiences respond to changes in advertising time in section 5.4.

\subsection{Audience Reactions to Advertising and Product Placement}

We use show dummies to control for unobserved program characteristics. Without show dummies, we would expect advertising responsiveness to be biased upward, since networks would include higher ad levels in programs with higher unobserved quality. As table 5 shows, without show dummies we find that both advertising and product placements have significant, positive effects on utility. This is counterintuitive as it suggests viewers enjoy watching advertising on average. When we add show dummies, the point estimates fall markedly, and advertising time is again significant, but this time with the opposite sign. These results indicate that show dummies mitigate some of the endogeneity issues associated with advertising.

Our other endogeneity controls are instrumental variables (IVs) for intertemporal variation in unobserved program characteristics and unobserved tune-in levels. We present the results of several tests of our IVs in the Technical Appendix. To summarize, we found that lags of advertising and product placements are useful instruments for current advertising and product 


\begin{tabular}{|c|c|c|}
\hline & $\begin{array}{l}\text { Results without } \\
\text { show dummies }\end{array}$ & $\begin{array}{r}\text { Results with } \\
\text { show dummies }\end{array}$ \\
\hline Ad Seconds & $\begin{array}{r}1.15 \mathrm{E}-04 \\
(3.00)\end{array}$ & $\begin{array}{r}-9.77 \mathrm{E}-05 \\
(3.03)\end{array}$ \\
\hline Product Placement Seconds & $\begin{array}{r}2.81 \mathrm{E}-05 \\
(2.25)\end{array}$ & $\begin{array}{r}-1.75 \mathrm{E}-05 \\
(1.38)\end{array}$ \\
\hline Adjusted $\mathrm{R}^{2}$ & 0.73 & 0.82 \\
\hline
\end{tabular}

Table 5. Multinomial Logit Estimates of Advertising and Product Placement Parameters

placement time, but using IVs does not materially affect the estimates. We proceed with MNL estimation without IVs on efficiency grounds. The point estimates imply the total effect of advertising is to significantly lower utility by about -0.029 (given that an average time slot has 300 seconds of advertising). This is a large effect relative to the increase in utility from watching a program.

In section 5.4, we consider what specification for $v\left(p_{n t}, q_{n t} ; \alpha\right)$ best fits the data. We know of no extant theory available to guide our selection. It seems reasonable to expect that viewers' marginal utility of advertising and product placement may be nonlinear. We followed two common procedures to select a functional form; both led to the same conclusion. First, we used splines with varying numbers of knots to estimate the shape of the advertising and product placement utility function. Second, we added powers of each term to a linear specification and stopped when the next power added was not statistically significant. Both methods indicated that $v\left(p_{n t}, q_{n t} ; \alpha\right)$ should be cubic in advertising time, and quadratic in product placement time. We found no evidence of interactions between advertising and product placement.

Recall we estimated the model separately for each demographic group. Figure 3 shows the estimated marginal utility of advertising for each of the three demographic groups. The household demographic group is less averse to advertising than the other two, but there is no apparent difference between adults 18-49 and adults 25-54. The differences emphasize how much more ad-averse adults 18-54 are than other viewers, since the households demographic group includes adults 18-49 and adults 25-54. Ad utility is everywhere decreasing, with an inflection point at 407 seconds. Just 16\% of observed ad levels exceed this inflection point. 


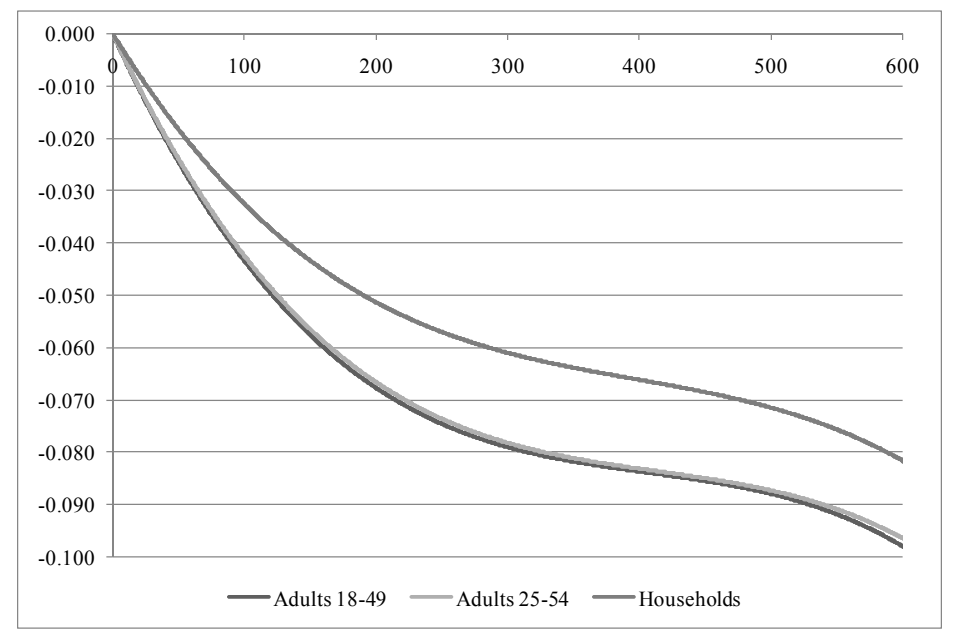

Figure 3. Estimated Marginal Utility of Ad Seconds

Figure 4 shows viewers' estimated marginal utility of product placement seconds. Product placement marginal utility is concave, but increasing and positive over most of the variable's range. Households appear to get the highest marginal benefit from product placement, followed by adults 25-54 and adults 18-49.

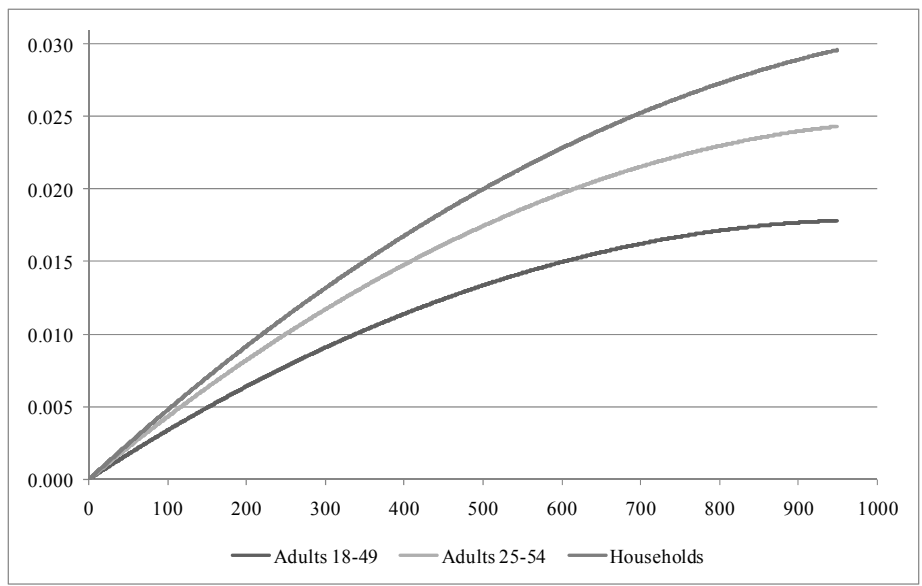

Figure 4. Estimated Marginal Utility of Product Placements

While we have included several endogeneity controls, the product placement results still may be biased. It could be the case that product placements are naturally accommodated by certain types of program scenes that contain unobserved characteristics that are attractive to viewers. For example, if high-budget program scenes are more likely to attract viewers, and contain increased levels of product placement, our finding of positive product placement marginal utility could be spurious. Such content could vary over episodes within a program and 
therefore escape the control provided by our program dummies. This problem seems unlikely to affect our advertising utility estimates since advertising content is less influenced by program content.

We collected some additional data to investigate this possibility. The website TV.com aggregates viewers' ratings of television programs and episodes. We supplemented these data with information from our sample, so we were able to separately control for episode quality and product placement. When we did this, we found that the estimated effect of product placement time on utility was negative and significant. We describe the procedure and results in detail in the Appendix. We report some additional results related to product placement characteristics in the Technical Appendix.

Adults 25-54 appear to have a nearly equal reaction to ads as adults 18-49. Households are the least valuable audience metric and seem to be least negatively affected by advertising. From here on, we focus on models estimated using audience data for adults $18-49$, as they are the group valued most highly by advertisers.

\subsection{Ad Utility by Product Category}

To estimate the effect of product category advertising on utility we set

$$
v\left(p_{n t}, q_{n t} ; \alpha\right)=\sum_{c} p_{c n t} \alpha_{c}^{p}+\sum_{c} q_{c n t} \alpha_{c}^{q}
$$

where $p_{c n t}$ is the product placement time given to brands in category $c$ on network $n$ in half-hour $t$, and $q_{c n t}$ is the corresponding ad time.

Table 6 gives the MNL significant estimates of $\alpha_{c}^{p}$ and $\alpha_{c}^{q}$. The results are as to be expected, as the highest significant category ad effects include movies, DVDs, light beer, regular beer, and four automotive categories. More surprising was the appearance of finance-related categories, including banks, insurance, and financial services. We reviewed some of these ads to try to understand the results further. Our general sense is that these ads contain higher entertainment value and production budgets than the typical ad, perhaps because they seek to capture consumer attention for products that might not otherwise be enjoyable to think about. The most-liked categories were corporate computing and participatory sports, though both represent a very small share of total advertising dollars. Corporate computing was dominated by 
a highly entertaining branding campaign by IBM, while the highest-spending brand in participatory sports was 1-800-SKYDIVE. ${ }^{18}$

Positive Category Advertising Effects ${ }^{\mathrm{a}}$

\section{Category}

Computers, Corporate

Participatory Sports

Light Beer \& Ale

Regular Beer \& Ale

Ice Cream

Home Audio Equipment

Financial Products and Services

Cars, European

Courier Services

Cars, Domestic

Motion Pictures

Insurance

Diet Carbonated Soft Drinks

Pre-Recorded Video \& DVDs

Banks, S\&Ls

Light Trucks, Asian

Light Trucks, Domestic

$0.0009(2.0)$

$0.0008(2.0)$

$0.0007(2.7)$

$0.0006(2.0)$

$0.0005(2.7)$
Point Est. \% All Ad \% All Ad

(T-Stat) Seconds Dollars Category

$\begin{array}{llll}0.0026(3.0) & 0.07 \% & 0.11 \% & \text { Prescription Medications }\end{array}$

$0.0024(2.8) \quad 0.03 \% \quad 0.06 \% \quad$ Wireless Telecom Providers

$0.0024(2.8) \quad 0.40 \% \quad 0.78 \% \quad$ Toothpaste \& Whiteners

0.0023 (5.6) $\quad 0.13 \% \quad 0.30 \% \quad$ Stationery, Greeting Cards

$0.0014(2.2) \quad 0.18 \% \quad 0.23 \% \quad$ Candy \& Mints

$0.0013(2.2) \quad 0.29 \% \quad 0.39 \% \quad$ Real Estate Agencies

$0.0013(2.6) \quad 0.32 \% \quad 0.36 \% \quad$ Cookies \& Crackers

$0.0012(2.7) \quad 0.46 \%$

$0.0012(3.3) \quad 0.35 \%$

$0.0012(2.7) \quad 0.75 \%$

$0.0011(4.5) \quad 5.76 \%$

$0.0010(8.7) \quad 0.31 \%$
$0.50 \%$

$1.86 \%$

$0.70 \%$

$1.83 \%$

$2.48 \%$
$0.62 \%$ Mouthwashes \& Breath Fresheners

$0.53 \%$ Diapers (Adult, Infant And Toddler)

$0.98 \%$ Bleach \& Fabric Softeners

$6.28 \%$ Spectator Sporting Events

$0.36 \%$ Shoe Stores

$0.65 \%$ Apparel

$1.92 \% \quad$ Pharmacies

$0.75 \%$ Vegetable Juices

$2.04 \%$

$3.28 \%$
Negative Category Advertising Effects ${ }^{\mathrm{a}}$

$\begin{array}{rrr}\text { Point Est. } \% \text { All Ad } \% \text { All Ad } \\ \text { (T-Stat) } & \text { Seconds } & \text { Dollars } \\ -0.0002(-2.7) & 7.06 \% & 6.33 \% \\ -0.0003(-2.6) & 6.09 \% & 6.05 \% \\ -0.0007(-2.1) & 0.59 \% & 0.57 \% \\ -0.0009(-3.4) & 0.48 \% & 0.37 \% \\ -0.0011(-2.9) & 0.62 \% & 0.53 \% \\ -0.0012(-3.0) & 0.54 \% & 0.46 \% \\ -0.0012(-2.3) & 0.32 \% & 0.28 \% \\ -0.0013(-2.9) & 0.37 \% & 0.30 \% \\ -0.0016(-2.3) & 0.14 \% & 0.11 \% \\ -0.0018(-2.4) & 0.12 \% & 0.10 \% \\ -0.0019(-2.5) & 0.14 \% & 0.09 \% \\ -0.0019(-2.0) & 0.14 \% & 0.11 \% \\ -0.0020(-2.1) & 0.08 \% & 0.09 \% \\ -0.0025(-3.0) & 0.08 \% & 0.07 \% \\ -0.0027(-2.3) & 0.07 \% & 0.06 \%\end{array}$

Table 6. Category Advertising Utility

The estimates indicate that viewers are averse to advertising in a variety of categories. Many are low-involvement categories like toothpaste, candy, cookies, and mouthwash. Others may have negative product associations such as diapers, vegetable juices, bleach, or pharmacies. Prescription medications and wireless telecommunications are the two highest spending categories that decrease average viewer utility. Prescription medication ad utility may be impacted by US Food and Drug Administration rules regarding disclosure of medication side effects.

\subsection{Ad Utility by Advertising Creative}

Our other substantive question is how individual advertisements vary in their effects on viewer utility. We respecify ad utility as

\footnotetext{
${ }^{18}$ Positive effects may be interpreted as categories whose ads discourage viewer switching in such a way as to increase Nielsen audience measurements, or capture the attention of viewers leaving other channels who then continue viewing the network.
} 


$$
v\left(p_{n t}, q_{n t} ; \alpha\right)=p_{n t} \alpha_{1}+p_{n t}^{2} \alpha_{2}+q_{0 n t} \alpha_{3}+q_{0 n t}^{2} \alpha_{4}+q_{0 n t}^{3} \alpha_{5}+\sum_{h=1}^{H} q_{h n t} \alpha_{h}
$$

where $q_{h n t}$ is the number of ad seconds devoted to creative $h$ on network $n$ at time $t, \alpha_{h}$ is the effect of creative $h$ on utility, and $q_{0 n t}$ is the amount of all ad time given to creatives that are not in the set $1 \ldots H$. We choose ad creatives to include in $H$ by following two steps. First, TNS creative names sometimes include an integer at the end, to indicate that the creative is a minor departure from a previously-logged commercial for the same brand. Typically these departures are 15 second versions of a 30-second ad, or a change in on-screen text in an otherwise identical ad. We drop this integer to pool across variations within an ad creative, yielding about 24,000 ad creatives in the sample. Second, we define a dummy variable for each of the 350 ad creatives that occurred on television most frequently during the sample period we use in estimation. Thus $H=350$. Each ad described by a creative-specific utility parameter appeared at least 42 times.

TNS Ad Creative Name
It's Ok To Look
Man Gets Locked Out In Bathrobe
Biggest Sale Of The Year
No Title Assigned - \#3726541
Man Drives Family To Gaze At Stars
Tunics/Women Dance On Boat
Duck Helps Couple Get By
Trainer Gets Pumped Up From Song
Vehicle Drives On Building Edges
Molly's Chambers/Couple Dances
Truck Performs Seesaw Ramp Trick
Woman Wakes Up In The Dark
Woman Had Mysterious Symptoms
People...To Do/Prescription Assistance
No Title Assigned - \#3978969
Bubbles Flow Over Bottle \& Teeth
Effortless Meticuless Fabuless
Father Says He Got Hosed
Lust For Life/Women In Europe
Family Shareplan/Man Talks To Family
Women Walk Around City In Shorts
Breast Meal/2Pc Meal/3 Strip Meal
Woman Acquires Boxes To Be Mailed
Man Offers People Fast Relief
Man Works At Vineyard
National Sales Race
Push It/I365 Nextel Phone
Tuscan Garlic Chicken
No Hassle Rewards/Man Skis In Summer
No Hassle Rewards/D Spade Answers No
People Rinse Their Mouth With Product
1500 Whenever Mins/Cheerleader On Phone
A Night In...Castle Giveaway/Letterbox
The Difference Between Services
Men \& Ellen At Reception Are Gellin
a
Mond

$\begin{array}{lrrr}\text { Brand } & \begin{array}{r}\text { Point Est. } \\ \text { (T-Stat) }\end{array} & \begin{array}{r}\text { \% of } \\ \text { all ads }\end{array} & \begin{array}{r}\text { dollars } \\ \text { dollar }\end{array} \\ \text { Match.Com Dating Service } & .005(2.1) & .04 \% & .02 \% \\ \text { Burlington Coat Factory Men } & .005(2.2) & .04 \% & .02 \% \\ \text { JC Penney } & .004(2.1) & .03 \% & .02 \% \\ \text { Boys \& Girls Club/Psa } & .003(2.4) & .04 \% & .04 \% \\ \text { Toyota Trucks Sequoia } & .003(3.3) & .09 \% & .11 \% \\ \text { Old Navy Clothing Store } & .003(2.4) & .05 \% & .07 \% \\ \text { Aflac Medical Insurance } & .003(2.2) & .04 \% & .04 \% \\ \text { Verizon Wireless Service } & .002(2.3) & .05 \% & .05 \% \\ \text { Ford Trucks Edge } & .002(2.0) & .04 \% & .09 \% \\ \text { Volkswagen Autos Jetta } & .002(3.0) & .06 \% & .10 \% \\ \text { Toyota Trucks Tundra } & .002(2.4) & .06 \% & .08 \% \\ \text { Lunesta Sleep Rx } & -.001(-2.2) & .08 \% & .15 \% \\ \text { Requip Restless Legs Syndrm Rx } & -.001(-2.0) & .04 \% & .07 \% \\ \text { Humira Rheumatoid Arthritis Rx } & -.001(-2.6) & .04 \% & .07 \% \\ \text { Foundation/Better Lf/Psa } & -.002(-2.2) & .08 \% & .08 \% \\ \text { Listerine Whitening Rinse } & -.002(-2.1) & .05 \% & .04 \% \\ \text { Target Disc Multi-Pdts } & -.002(-2.1) & .04 \% & .06 \% \\ \text { Verizon Wireless Service } & -.002(-2.1) & .05 \% & .04 \% \\ \text { Royal Caribbean Cruises } & -.002(-2.6) & .06 \% & .07 \% \\ \text { Verizon Wireless Service } & -.002(-2.3) & .05 \% & .04 \% \\ \text { Old Navy Clothing Store } & -.002(-2.2) & .04 \% & .06 \% \\ \text { KFC Restaurant } & -.002(-2.3) & .05 \% & .05 \% \\ \text { USPS.com } & -.003(-2.5) & .05 \% & .03 \% \\ \text { Zantac 150 } & -.003(-2.1) & .03 \% & .03 \% \\ \text { Claritin Allergy Remedy } & -.003(-2.4) & .07 \% & .05 \% \\ \text { Nissan Autos Altima \& Sentra } & -.003(-2.0) & .04 \% & .03 \% \\ \text { Sprint PCS Wireless Service } & -.003(-2.0) & .03 \% & .03 \% \\ \text { Olive Garden Restaurant } & -.003(-2.1) & .06 \% & .05 \% \\ \text { Capital One Mastercard \& Visa } & -.003(-3.0) & .05 \% & .04 \% \\ \text { Capital One Mastercard \& Visa } & -.003(-2.3) & .05 \% & .06 \% \\ \text { Listerine Mouthwash } & -.003(-2.2) & .04 \% & .03 \% \\ \text { T-Mobile Wireless Service } & -.003(-4.3) & .09 \% & .09 \% \\ \text { Disneyparks.Com Online } & -.004(-3.3) & .04 \% & .03 \% \\ \text { Blockbuster.Com Store Online } & -.004(-3.6) & .04 \% & .04 \% \\ \text { Dr Scholls Massaging Gel Insoles } & -.004(-2.3) & .05 \% & .03 \%\end{array}$

${ }^{a}$ Only ad creative effects significant at the $95 \%$ level are shown.

Table 7. Ad Creative Utility 
Of the 350 ad creative parameters, 35 were estimated to be significant at the $95 \%$ confidence level. Table 7 displays the creative names, brands, parameter estimates, and tstatistics for each of those creatives. It also shows what fraction of all ads and ad dollars in the sample each creative accounted for.

We interpret these results with caution. We presume that most of the ad creatives in the sample have some effect on viewer utility, and we would be able to measure all of their effects if we had individual-level viewing data. We are looking here at the tails of the distribution of ad creative utility, among the ads that appeared most frequently.

With those caveats in mind, it is interesting to note what these ads do not have in common. It does not appear that brand identity is a primary driver of ad creative utility, as two brands (Verizon Wireless and Old Navy) have ad creatives with significant positive effects, as well as ad creatives with significant negative effects. However, none of the significant creative effects contradict the positive and negative category-specific effects presented above.

We watched the ads in Table 7 to try to get a general sense of what creative elements drive the results. We noticed that ads with significant positive effects tended to be upbeat and affirmative, and to feature actors that appeared younger than about 40 years old. One advertisement featured a popular celebrity (Denzel Washington) and another had a song from a popular band (Kings of Leon).

Ad creatives with significant negative effects were more likely to feature actors older than forty, convey negative messages, and depict scenes of frustration. Some contained what could be subjectively termed annoying stimuli, such as intentionally bad dancing ("Push It/1365 Nextel Phone"), high-pitched, rapid speech ("1500 Whenever Mins/Cheerleader on Phone"), or actors using made-up words in conversation ("Men and Ellen at Reception are Gellin").

The results suggest that, consistent with Woltman Elpers et al. (2003) and Teixeira et al. (2008), creative characteristics drive viewer acceptance of advertising. While we find these effects to be interesting, they are suggestive at best. We think there is scope for future research to use individual-level data to measure the effects of ad creative characteristics on viewers' advertising utility. 


\subsection{Random coefficients logit results}

In this section we present results from the full random coefficients logit model, including the estimated elasticities of advertising. Our advertising utility specification is given by

$$
v\left(p_{n t}, q_{n t} ; \alpha_{i}\right)=p_{n t} \alpha_{1 i}+p_{n t}^{2} \alpha_{2}+q_{n t} \alpha_{3 i}+q_{n t}^{2} \alpha_{4}+q_{n t}^{3} \alpha_{5} .
$$

The main results are shown in Table 8 . The point estimates of advertising and product placement have the same signs as those estimated in the multinomial logit model, but are not estimated as precisely. Most of the significant effects are those associated with the program dummies, network-day dummies, and half-hour dummies. Table 9 presents the highest estimated program effects. The top programs seem reasonable: American Idol, Desperate Housewives, Grey's Anatomy, and Lost. Table 10 shows the network-weekday point estimates. One of the highest significant estimates is NBC's Thursday night, which is the only network-day to be branded in recent years ("Must See TV").

\begin{tabular}{|c|c|c|}
\hline Regressor & Joeff. Est. (T-Stat) & Stat) \\
\hline Ad Sec. & $-.00113(-0.2)$ & $0.1(0.0)$ \\
\hline$(\mathrm{Ad} \mathrm{Sec} .)^{2}$ & $.00000(0.0)$ & \\
\hline$(\mathrm{Ad} \mathrm{Sec} .)^{3}$ & $.00000(0.1)$ & \\
\hline PP Sec. & $.00000(-0.1)$ & $0.3(0.0)$ \\
\hline$(\text { PP Sec. })^{2}$ & $.00000(-0.6)$ & \\
\hline NewEps & $1.48984(0.6)$ & \\
\hline 1-week lag $s_{n t}$ & $.04335(0.5)$ & \\
\hline 2-week lag $s_{n t}$ & $.01432(0.3)$ & \\
\hline 3-week lag $s_{n t}$ & $.00989(0.1)$ & \\
\hline 4-week lag $s_{n t}$ & $.01269(0.3)$ & \\
\hline 5-week lag $s_{n t}$ & $.01376(1.2)$ & \\
\hline Constant & $.18429(1.3)$ & \\
\hline GMM Objective & & 8.4558 \\
\hline Pseudo $\mathrm{R}^{2}$ & & 0.7499 \\
\hline
\end{tabular}

Table 8. Random Coefficients Model Parameter Estimates

\section{Program}

Program: American Idol

Program: Desperate Housewives

Program: Grey's Anatomy

Program: Lost

Program: House

Program: 20/20

Program: 24
Coeff. Est. (T-Stat)

6.8E-1 (2.2)

5.9E-1 (4.6)

$5.3 \mathrm{E}-1(5.4)$

5.2E-1 (3.2)

4.4E-1 (1.7)

3.4E-1 (2.0)

3.3E-1 (2.6)

Table 9. Selected Random Coefficent Model Program Fixed Effect Estimates 


$\begin{array}{lrlr}\text { Regressor } & \text { Coeff. Est. (T-Stat) } & \text { Regressor } & \text { Coeff. Est. (T-Stat) } \\ \text { ABC-Mon } & 0.18(1.3) & \text { FOX-Mon } & 0.24(2.5) \\ \text { ABC-Tue } & 0.13(1.5) & \text { FOX-Tue } & 0.20(1.2) \\ \text { ABC-Wed } & 0.11(1.4) & \text { FOX-Wed } & 0.27(2.7) \\ \text { ABC-Thu } & 0.15(1.8) & \text { FOX-Thu } & 0.11(1.0) \\ \text { ABC-Fri } & -0.23(-1.8) & \text { FOX-Fri } & -0.31(-1.9) \\ \text { ABC-Sat } & -0.29(-2.0) & \text { FOX-Sat } & 0.39(0.7) \\ \text { CBS-Sun } & 0.25(0.9) & \text { NBC-Sun } & 0.05(0.3) \\ \text { CBS-Mon } & 0.48(2.7) & \text { NBC-Mon } & 0.27(2.6) \\ \text { CBS-Tue } & 0.20(1.5) & \text { NBC-Tue } & 0.23(0.7) \\ \text { CBS-Wed } & 0.15(1.5) & \text { NBC-Wed } & 0.07(0.8) \\ \text { CBS-Thu } & 0.45(1.6) & \text { NBC-Thu } & 0.40(3.1) \\ \text { CBS-Fri } & 0.04(0.2) & \text { NBC-Fri } & -0.03(-0.2) \\ \text { CBS-Sat } & 0.08(0.3) & \text { NBC-Sat } & -0.13(-0.7) \\ \text { FOX-Sun } & 0.49(2.5) & \text { WB-Thu } & -0.26(-1.8) \\ \text { Note: ABC-Sun was chosen to be the excluded night. With one } \\ \text { exception (WB-Thu), all CW-, UPN-, and WB-Weekday interactions } \\ \text { were dropped due to scarcity of top-100 audience observations on those } \\ \text { nights. }\end{array}$

Table 10. Random Coefficent Model Estimates of Network-Weekday Effects

We used the parameter estimations to compute median advertising elasticites (for details see the technical appendix) presented in Table 11. The elasticities indicate that if a broadcast network unilaterally increases its advertising time by $10 \%$, its median audience loss is about $15 \%$. The cross-elasticities are roughly comparable in nature across the "inside" networks and the outside option, but since the market share of the outside option is much larger than the sum of the ratings of the inside networks, this implies that when viewers leave an audience in response to an additional advertisement, they usually turn away from broadcast television altogether (tuning to a cable network, for example).

It is interesting to compare our elasticity estimates to those of Wilbur (2008b). He estimated a similar model using four weeks of audimeter/diary audience data from a crosssection of local markets. He found that a $10 \%$ rise in advertising time caused a median $25 \%$ audience loss on highly-rated networks, and larger percentage audience losses for low-rated networks. Our elasticities are smaller and more homogeneous by comparison, though still substantial. The difference in our estimates can perhaps be attributed to the unreliability of diary data, which places a much higher burden on the audience member than the Peoplemeter technology used to produce our sample. 


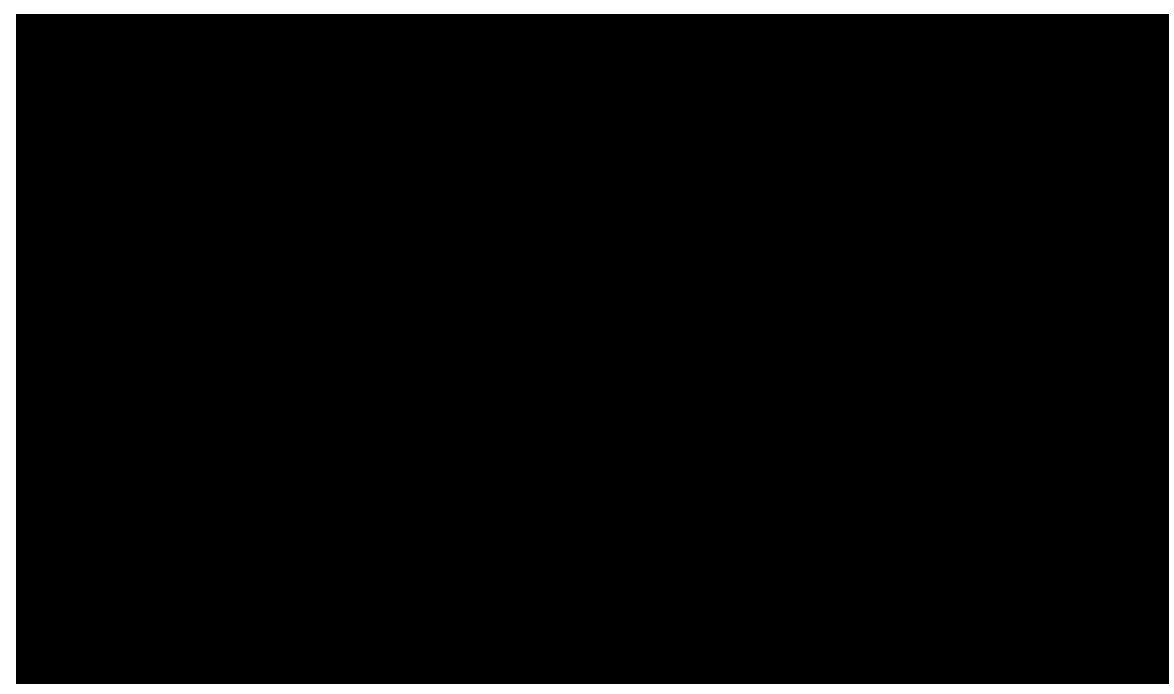

Table 11. Random Coefficent Model Median Estimated Elasticities of Advertising.

\section{Discussion}

In light of the increasing importance of advertisement avoidance, we estimated a model of television viewing demand in which viewing decisions depend on program characteristics, scheduling factors, advertising time and characteristics, and product placement time and characteristics. Our key findings are that a unilateral 10\% increase in advertising reduces a network's audience by a median $15 \%$, and audience responses to advertising seem to be driven by product category and ad content. When we control for episode quality, we find that product placement has a negative effect on viewer utility.

Our findings imply that networks ought to price discriminate among advertisers in order to maximize audience retention throughout their commercial breaks. There are three ways this could be done in practice. The simplest way would be to give ad price breaks to advertisers in categories which have traditionally been associated with high-utility ad creatives, such as beer, autos, movies, and finance-related categories. Accordingly, higher prices could be charged to those advertisers in categories that historically cause larger audience losses.

A more nuanced way to implement this would be to set up a system whereby advertisers submit their creatives to standardized tests of audience acceptance. For example, an ad creative could be vetted by an online consumer panel or inserted into network programming online (e.g., on Hulu.com), and observed viewer reactions could be used to measure viewer response to the ad. Given enough consumers in the panel and a standard approach toward testing creatives, a 
formula could be devised to adjust the advertiser's price. The attraction of this idea is that it would give advertisers an increased incentive to produce engaging advertising, and could possibly correct the currently unpriced externality in which an ad's audience loss harms subsequent advertisers in the commercial break.

A third approach would be to base ad prices on more granular television audience measurements, such as second-by-second ratings currently extractable from the universe of digital cable boxes and digital video recorders (Wilbur 2008a). This would give advertisers the strongest incentives to avoid causing audience losses. However, it would be the most difficult to implement, since ownership of the most granular viewing data resides with multiple parties with potentially conflicting interests, and the television industry has historically been slow to agree upon and implement new metrics.

We view all three of these suggestions as realistic. The first can feasibly be implemented right away, while the second probably needs to be refined after a design and testing phase. The third suggestion is the most difficult to set up, but would have the most positive impact on the television industry's collective health in the long run. It would also likely have the greatest effect on viewer welfare, which is consequential in an industry with such a large share of gross domestic leisure time.

Like all models, ours has several limitations which suggest directions for future research. We have not modeled viewer uncertainty about advertising and product placement time, as Anand and Shachar $(2004,2005)$ did in a related context. This is difficult to do reliably using aggregate rating data, but may be feasible using the approaches of Chen and Yang (2007) or Musalem, Bradlow and Raju (forthcoming). We also have not controlled for order of advertisement presentation. Finally, while we have used the best audience data available to us, there is scope for estimating a similar model using more granular data, such as commercial minute ratings or second-by-second set-top box data. 


\section{Technical Appendix.}

\section{TA.1. Model}

The number of parameters in $\Phi, K$, can be as large as the combined dimensions of $\alpha_{i}$ and $\beta_{i}$, but is typically chosen to be smaller, as estimation time increases exponentially in $K$. We could include individual demographics drawn from population-level distributions in Equation (2), but given that we do not have meaningful variation in viewer demographics over markets or time, it is not clear that these effects would be separately identified from $\Phi$.

We can rewrite equation 1 as

$$
u_{i n t}=\delta_{n t}+\mu_{i n t}+\varepsilon_{i n t}
$$

where $\delta_{n t}=v\left(p_{n t}, q_{n t} ; \alpha\right)+X_{n t} \beta+\xi_{j}+\eta_{n t}$ captures the base utility every viewer derives from network $n$ at time $t$. The composite random shock, $\mu_{\text {int }}+\varepsilon_{\text {int }}$, captures viewer preference heterogeneity.

\section{TA.2. Data}

There were a few programs that appeared on more than one network over the course of the sample. When this occurred, we defined a separate program-network for each instance of the program.

Our unit of observation is a date-network-half-hour, but a network occasionally aired more than one program per half-hour slot. This affected less than $1 \%$ of the half-hours in our sample and was usually related to sports programming. For example, a game ran longer than its scheduled timeslot, or a half-hour included both a "pre-game show" and part of a game (two separate programs for which we observe separate audience ratings). We therefore had to choose which program's audience rating to assign to some date-network-half-hours shared by two programs. We followed a two-step procedure. If exactly one of the two programs did not appear in any other half-hours, then we assigned that program's audience rating to the half-hour. If both programs spanned multiple half-hours, then we assumed the program that contained more advertising during the date-network-half-hour in question accurately reflected the true audience rating. It was never the case that neither program spanned multiple half-hours.

We do not observe advertisements networks aired for their upcoming programs ("tuneins" or "promos"), as TNS' ad-recording software was not able to distinguish tune-ins from network programs. Time given to tune-ins is a potentially important omitted variable. A 2001 report found that networks aired 4:07 minutes of tune-ins per hour. This compared with 9:44 minutes of advertising, and tune-ins and traditional advertising time had a correlation of -0.31 
(AAAA/ANA 2001). In section TA.3, we discuss potential endogeneity issues arising from not observing tune-ins and how we control for these in estimation.

We observe an audience rating for each demographic group whose top-100 list included that program. We do not observe a program's audience rating if it falls short of the 100th-highest audience rating in the week it aired. Therefore our measure of the outside good incorporates programs that are not listed in the top-100. We were concerned that when we have a program that appears on the top-100 list in some weeks and sometimes does not appear, then the error term might not be orthogonal to the observed data. We calculated the prevalence of this issue in the dataset. We found that $98.7 \%$ of the network-half-hour observations in the audience data belong to programs that always appear on the top-100 list. Thus this doesn' not appear to be an issue.

We use two sets of instruments to address potential remaining endogeneity issues: lags of advertising time, and lags of product placement time. Traditional advertising time and product placement seconds are autocorrelated (1-week correlations of 0.42 and 0.44 , respectively), so lags are good proxies for current advertising time and product placements. Their exclusion from the viewer utility function is justified if networks are myopic when setting traditional advertising time and product placements. ${ }^{21}$

We follow standard procedures to test the usefulness of lags of ad seconds and product placement seconds as instruments for current ad seconds and product placement time (see, e.g., Baum, Schaffer, and Stillman 2003). We follow three steps. The first is to use F-tests to determine whether the proposed instruments jointly explain the endogenous variables in the first stage. The second step is to use F-tests to determine whether the system of instrumental variables is overidentified. This test requires that at least two of the instruments are valid (e.g., the fifth lags of advertising and product placement), and is sometimes not employed because it can have low power, suggesting that using it may lead us to fail to reject a false hypothesis (Small 2007). However we note that the absence of an overidentification test has no power, ensuring that we will fail to reject a false hypothesis; thus, we present the overidentification test in conjunction with the theoretical arguments above. The third step is to use a Hausman specification test to gauge the difference between the OLS and IV estimates. The third step checks whether IV estimation changes the point estimates of the endogenous regressors. If it does not change the estimates, we retain MNL non IV estimates on efficiency grounds.

Table TA1 displays the results of the first two steps. The first column of the table presents results from the first-stage regression of advertising seconds on the proposed instruments and the exogenous variables in the viewer utility function. Lags of advertising

${ }^{21}$ Our approach is similar to much of the marketing literature (e.g., Villa-Boas and Winer 1999) which uses lagged values of strategic variables to proxy for contemporaneous values. 
seconds are significant and the F-test rejects the null hypothesis that the candidate instruments jointly do not explain the dependent variable at a high confidence level. The second column of the table indicates that the instruments jointly explain product placement seconds to a similar degree. The third column tests the joint significance of the instruments in the second-stage equation. The F-statistic fails to reject the null that the instruments do not jointly explain the logtransformed program ratings. Thus we conclude that lags of advertising and product placement time are valid instruments for current advertising and product placement time, conditional on the theoretical restrictions related to the overidentification test noted above.

Finally, we compare the parameter estimates under OLS and IV. If there is no significant difference, OLS results are preferred on efficiency grounds. The Hausman test fails to reject the null that the OLS estimates are different from the IV estimates. Thus the use of these instruments does not change the estimated effects of the potentially endogenous variables enough to justify the loss of efficiency associated with IV estimation.

$\begin{array}{lrrr} & \begin{array}{r}\text { First-stage Est. } \\ \text { in AdSec Eqn. }\end{array} & \begin{array}{r}\text { First-stage Est. } \\ \text { in PP Eqn. } \\ \text { Instrument }\end{array} & \begin{array}{r}\text { Second-Stage } \\ \text { Est. in Viewer } \\ \text { Demand Eqn. }\end{array} \\ \text { Ad Seconds } & & & \\ \text { 1st Lag } & 0.16(17.38) & -0.03(-1.53) & 4.5 \mathrm{E}-5(1.39) \\ \text { 2nd Lag } & 0.13(13.64) & 0.01(0.34) & 4.4 \mathrm{E}-6(0.14) \\ \text { 3rd Lag } & 0.09(9.89) & -0.02(-0.99) & 8.0 \mathrm{E}-6(0.25) \\ \text { 4th Lag } & 0.09(9.33) & 0.00(0.2) & -1.7 \mathrm{E}-5(-0.54) \\ \text { 5th Lag } & 0.09(10.47) & 0.01(0.62) & -3.3 \mathrm{E}-5(-1.07) \\ \text { Product Placement Seconds } & & & \\ \text { 1st Lag } & 2.0 \mathrm{E}-3(0.6) & 0.06(7.18) & -2.9 \mathrm{E}-5(-2.51) \\ \text { 2nd Lag } & 4.2 \mathrm{E}-3(1.29) & 0.03(3.5) & -2.5 \mathrm{E}-6(-0.22) \\ \text { 3rd Lag } & -5.7 \mathrm{E}-3(-1.57) & 0.03(3.28) & 1.7 \mathrm{E}-5(1.4) \\ \text { 4th Lag } & -2.5 \mathrm{E}-3(-0.7) & 0.03(3.81) & -8.5 \mathrm{E}-6(-0.68) \\ \text { 5th Lag } & 4.1 \mathrm{E}-4(0.11) & 0.04(4.53) & 1.8 \mathrm{E}-6(0.14) \\ & & & \\ \text { Null Hypothesis } & \text { No joint effect } & \text { No joint effect } & \text { No joint effect } \\ \mathrm{R}^{2} \text { in unrestricted model } & 0.4383 & 0.6307 & 0.8315 \\ \mathrm{R}^{2} \text { in restricted model } & 0.3316 & 0.6231 & 0.8313 \\ \text { Joint Significance F-Stat } & 173.26 & 18.73 & 1.08 \\ \text { 99\% Critical Value } & 2.32 & 2.32 & 2.32 \\ \text { P-Value } & \mathbf{0} & \mathbf{1 . 7 1 E}-34 & \mathbf{0 . 3 7} \\ \text { Result } & \text { Reject Null } & \text { Reject Null } & \text { Don't Reject Null } \\ & & & \end{array}$

Table TA1. Instrumental Variables Tests 


\section{TA.3 Identification}

We discuss informally what variation in the data identifies the parameters. Associated with each network-half hour is a mean utility, $\delta_{n t}$, which is chosen to match observed and predicted audience ratings. Audience levels identify the show, network-day, week, and half-hour effects. Holding these characteristics constant, correlations between audience, advertising, and product placement over time identify the mean utility parameters associated with advertising and product placement.

In practice we cannot estimate a separate dummy for every show in the sample. Thus we assign a show dummy to as many shows as possible, where the remaining shows are described by NewEps, network-day, season-week, half-hour, and genre effects. Some genre effects are dropped because they are highly collinear with the set of show dummies for the shows belonging to that genre. We are able to separately identify show effects from network-time effects because of the rich scheduling variation over the three-year sample period. The taste parameters, $\beta$ and $\alpha$, associated with non-time changing $X_{n t}$ are identified using a minimum distance procedure outlined in the next section. The idenfication strategy follows Nevo (2000) who shows that the two-step estimate technique we employ, together with the assumption that the $\xi_{n t}$ are mean independent of other program characteristics, allows for identification of the mean random coefficient. ${ }^{22}$

Identification of the taste distribution parameters, $\Phi$, relies on patterns of viewer substitution between shows. While the means are identified by audience sizes, the standard deviations are identified by the "stickiness" of how those audience sizes change when faced with variation in show competition, advertising, and product placements on competing networks within the same half-hour.

\section{TA.4. Estimation}

The first step is to match the model's predicted ratings to observed ratings. We seek the vector $\delta\left(S_{t}^{o b s}, \theta\right)$ that implicitly solves

$$
S_{t}^{o b s}-S_{t}(\delta, \theta)=0
$$

where $S_{t}^{o b s}$ and $s_{t}$ are $N_{t}$-vectors of observed and predicted audience ratings respectively and $\theta$ represents the complete parameter set. For each guess of $\theta$, we start with an initial set of mean utilities $\delta_{n t}^{0}$, calculate $s_{n t}^{0}\left(\delta_{n t}^{0}, \theta\right)$, construct a new guess $\delta_{n t}^{1}(S, \theta)=\delta_{n t}^{0} \frac{S_{n t}^{o b s}}{s_{n t}\left(\delta_{n t}^{0}\right)}$, and repeat these last two steps $r$ times until $\left|\delta_{n t}^{r}\left(S_{t}^{o b s}, \theta\right)-\delta_{n t}^{r-1}\left(S_{t}^{o b s}, \theta\right)\right|$ is arbitrarily close to zero $\left(10^{-14}\right.$ in our application). We then calculate the structural error term substituting $\delta_{n t}^{r}\left(S_{t}^{\text {obs }}, \theta\right)$ for $\delta_{n t}$. The error term is given by

\footnotetext{
${ }^{22}$ As Nevo (2000) shows, this procedure is equivalent to a GLS regression where the independent variable consists of the estimated program effects. The number of "observations" in this regression is the number of programs. Please see Nevo (2000) for more detail.
} 


$$
\Delta \xi_{n t}(\theta)=\delta_{n t}^{r}\left(S_{t}^{o b s}, \theta\right)-\left(v\left(q_{n t}, p_{n t} ; \alpha_{i}\right)+X_{n t} \beta+\xi_{j}\right) .
$$

We search over $\theta$ to minimize the GMM objective function

$$
\left(Z^{\prime} \Delta \xi\right)^{\prime} \Omega^{-1}\left(Z^{\prime} \Delta \xi\right),
$$

where $\Delta \xi=\left\{\Delta \xi_{n t}\right\}$ is the $N \mathrm{x} 1$ error term, and $\Omega$ is a weighting matrix. As an initial guess we set $\Omega=Z^{\prime} Z$ to get a consistent estimate of $\hat{\Omega}=\left(Z^{\prime} \Delta \xi\right)\left(Z^{\prime} \Delta \xi\right)^{\prime}$, which we use in the final parameter estimation.

The BLP estimation routine has the desirable property that it is linear in preference means, which greatly speeds computation by reducing the number of parameters that enter the objective function nonlinearly. However it is still nonlinear in the standard deviations of the preference distributions, and computation time increases exponentially with the number of nonlinear parameters to be estimated. We restrict the number of parameters interacting with unobserved viewer heterogeneity to two: those multiplied by the terms $p_{n t}$ and $q_{n t}$ (i.e. $K=2$ ). To simulate individual television viewers, we invert the Normal distribution at 500 multivariate Halton draws for each random utility parameter, and use antithetic acceleration to produce 500 more draws to reduce simulation variance. ${ }^{23}$ Thus our total number of simulated viewers is 1,000. The data we use in estimation is the final seven weeks of the 2004-05 season, since product placement data were not available until March 28, 2005; and weeks 6-35 of the 2005-06 and 2006-07 seasons, since we have weekly five lags of audience and ad price per viewer in our utility specification. ${ }^{24}$

The primary reason to estimate the random coefficients logit model is that its estimated elasticities do not exhibit the well-known independence of irrelevant alternatives problem. The advertising elasticities generated by this model are

$$
\frac{\partial s_{n t} q_{m t}}{\partial q_{m t} s_{n t}}=\left\{\begin{array}{l}
-\frac{q_{n t}}{s_{n t}} \int \frac{\partial v_{i}}{\partial q_{n t}} s_{i n t}\left(1-s_{i n t}\right) d F\left(v_{i}\right), \text { if } m=n \\
\frac{q_{m t}}{s_{n t}} \int \frac{\partial v_{i}}{\partial q_{n t}} s_{i n t} s_{i m t} d F\left(v_{i}\right), \text { if } m \neq n
\end{array} .\right.
$$

The elasticities in equation TA5 contain $s_{\text {int }}$, the probability that simulated individual $i$ picks alternative $n$ at time $t$, given a change in ad time $q_{m t}$. Therefore substitution patterns are not

\footnotetext{
${ }^{23}$ For more on antithetic acceleration see Stern $(1997,2000)$. Geweke (1988) shows if antithetic acceleration is implemented during simulation, then the loss in precision is of order $1 / \mathrm{N}$ (where $\mathrm{N}$ is the number of observations), which requires no adjustment to the asymptotic covariance matrix.

${ }^{24} \mathrm{We}$ used logit results for starting values for parameter means, and evaluated the objective function at 1000 points in a grid search to find starting values for the random coefficients. We found many local minima, but when drawn over the range of grid points we sampled, the objective function looks convex to the eye in both dimensions of $\theta$. Computation time was about five days on a $3.2 \mathrm{GHz}$ computer using serial processing.
} 
driven by aggregate market shares irrespective of program characteristics, as in the multinomial logit model, but instead they are calculated as the aggregation of simulated discrete choices. Also notable is that the model produces a different elasticity for each network-half hour.

\section{TA.5. Serial Correlation}

As noted in section 2, we have included five weekly lags of the network's weekday-timeslot rating to control for audience state dependence. If $\Delta \xi$ is serially correlated, including these lagged audience shares will pick up the effects of previous values of the error term. Serial correlation therefore will not bias the effects of advertising and product placement, since this correlation exists between observed variables. Therefore it is possible that the effects of the state dependence terms are biased.

\section{TA.6. Interpreting Estimation Results}

Implicit in our interpretation of our advertising and product placement results is the assumption that product category advertisements do not correlate with unobserved audience propensity to switch channels in response to advertising. For example, if Light Beer ads always appear during very popular sports events, and viewers of very popular sports events never change channels during commercials, we could find spurious positive effects of Light Beer ads on audiences. We think this possibility is interesting but unlikely. We see in the data substantial variation in the programs and genres in which category ads appear. For example, Light Beer ads appear in many, many different programs and genres, and those brands would have to continually appear in the episodes of programs during which viewers were least likely to switch. Individual level viewing data would likely be most effective in examining this hypothesis.

\section{TA.7. Additional Product Placement Results}

Table TA2 presents parameter estimates measuring the impact of product placement characteristics on viewer utility. We include in $X_{n t}$ the product placement characteristics described in section 3.3. $X_{n t}$ includes $x_{l n t}$, the fraction of product placement seconds on network $n$ during half-hour $t$ that have characteristic $l$. In this way we are able to separately control for the amount of placements during the program and the types of placements observed. The estimates are small in magnitude or not statistically significant suggesting that product placement characteristics are not driving program viewing decisions. Table TA3 displays the estimates for product placement category effects. 


$\begin{array}{ll} & \text { Variable } \\ \text { Type } & \text { Verbal Only } \\ & \text { Direct Visual Only } \\ & \text { Implied Visual Only } \\ & \text { Verbal \& Direct Visual } \\ & \text { Verbal \& Implied Visual } \\ \text { Appearance } & \text { Product or Package shown } \\ & \text { Brand Name shown } \\ & \text { Brand Mark shown } \\ & \text { Billboard or Graphic Overlay } \\ & \text { No Visual } \\ \text { Interaction } & \text { Interaction w/ Real Life Persona } \\ & \text { Interaction w/ Fictional Character } \\ & \text { No Interaction } \\ \text { Visual } & \text { Foreground } \\ \text { Location } & \text { Background }\end{array}$

Point Est.

(T-Stat)

$.06(0.9) \quad$ Integration

$-.02(0.7)$

$-.03(1.1)$

$-.04(1.0)$

$$
.04(0.8)
$$

$.02(0.4) \quad$ Visibility

$.05(1.1)$

$.05(0.8)$

-- Clutter

$-.08(1.3)$

$-.04(0.7) \quad$ Visual

-- Interaction

.01 (0.6) Type
Variable

Integration as a Prize or Reward Integrated Directly into Game/Contest Integrated Partially Into Game/Contest Integration as a Sponsorship

Other Integration

No Integration

Fully Visible

Partially Visible

Not Applicable

No Clutter

Clutter

Brand Interaction

Product Interaction (Proper Use)

Product Interaction (Improper Use)

No Interaction
Point Est.

(T-Stat)

$.00(0.1)$

$.04(1.0)$

$-.09(1.5)$

$.02(0.8)$

$.04(1.8)$

$-.01(0.5)$

$-.02(0.6)$

$.00(0.0)$

$.06(0.9)$

$.04(0.6)$

$.08(1.1)$

\section{Table TA2. Product Placement Characteristics Estimates}

\section{Positive Category Product Placement Effects ${ }^{\mathrm{a}}$}

Category
Gelatins and Puddings
Regular Beer \& Ale
Cosmetics \& Beauty Aids
Regular Carbonated Soft Drinks
Sneakers
Motion Pictures

Point Est. \% All PP

(T-Stat) Seconds

$0.0014(2.0)$

$0.0007(2.0)$

$0.0006(2.1)$

$0.0003(4.7)$

$0.0002(3.0)$

$0.0002(2.7)$

$0.10 \%$

$0.42 \%$

$0.46 \%$

$10.37 \%$

$3.14 \%$

$1.53 \%$
Negative Category Product Placement Effects ${ }^{\mathrm{a}}$

Category

Point Est. \% All PP

(T-Stat) Seconds

Apparel

Pre-Recorded Video

Corporate Advertising

$-0.0003(-2.7) \quad 1.64 \%$

$-0.0003(-4.6) \quad 1.09 \%$

$-0.0004(-2.4) \quad 0.53 \%$

$-0.0005(-2.0) \quad 0.91 \%$

$\begin{array}{lll}\text { Cars, Domestic } & -0.0007(-2.0) & 0.48 \% \\ \text { Wireless Telecom Providers } & -0.0007(-4.2) & 1.77 \%\end{array}$

$\begin{array}{lll}\text { Wireless Telecom Providers } & -0.0007(-4.2) & 1.77 \% \\ \text { Internet Service Providers } & -0.0008(-4.7) & 0.89 \%\end{array}$

Credit Cards

$-0.0012(-2.4) \quad 0.29 \%$

Prepared Dinners \& Entrees $\quad-0.0022(-2.7) \quad 0.09 \%$

Employment Agencies $\quad-0.0054(-3.3) \quad 0.12 \%$

Medical Supplies

$-0.0070(-2.3) \quad 0.04 \%$

${ }^{\text {a }}$ Only effects significant at the $95 \%$ confidence level are shown.

Table TA3. Category Product Placement Utility 


\section{References}

American Association of Advertising Agencies, Association of National Advertisers (AAAA/ANA). 2001. Television Commercial Monitoring Report. Mimeo.

Anand, B., R. Shachar. 2004. Brands as Beacons: a New Source of Loyalty to Multiproduct Firms. Journal of Marketing Research, 41 (2): 135-150.

Anand, B., R. Shachar. 2005. Advertising, the Matchmaker. Mimeo, Tel Aviv University.

Anderson, S. P., S. Coate. 2005. Market Provision of Broadcasting: a Welfare Analysis. Review of Economic Studies, 72(4): 974-972.

Anderson, S. P., J. Gabszewicz. 2006. The Media and Advertising: a Tale of Two-Sided Markets. Forthcoming in Handbook of Cultural Economics, eds. Victor Ginsburgh and David Throsby, Elsevier: North Holland.

Arellano, M., S. Bond. 1991. Some Tests of Specification for Panel Data: Monte Carlo Evidence and an Application to Employment Equations. Review of Economic Studies, 58: 277297.

Balasubramanian, S. K., J. A. Karrh, H. Patwardhan. 2006. Audience Response to Product Placements. Journal of Advertising, 35(3): 115-141.

Baum, C. F., M. E. Schaffer, S. Stillman.2003. Instrumental Variables and GMM: Estimation and Testing. Stata Journal

Berry, S. 1994. Estimating Discrete Choice Models of Product Differentiation. RAND Journal of Economics, 25, 242-262.

Berry, S., J. Levinsohn, A. Pakes. 1995. Automobile Prices in Market Equilibrium. Econometrica, 63, 841-890.

Bound, J., D. A. Jaeger, R. M. Baker. 1995. Problems with Instrumental Variables Estimation when the Correlation between the Instruments and the Endogenous Explanatory Variable is Weak. Journal of the American Statistical Association, 90, 433-450.

Chamberlain, G. 1987. Asymptotic Efficiency in Estimation with Conditional Moment Restrictions. Journal of Econometrics, 34: 305-344.

Chen, Y., S. Yang. 2007. Estimating Disaggregate Models using Aggregate Data via Augmentation of Individual Choice. Journal of Marketing Research, 4: 596-613.

Danaher, P. J. 1995. What Happens to Television Ratings during Commercial Breaks? Journal of Advertising Research, 35(1): 37-42.

Depken II, C. A., D. P. Wilson. 2004. Is Advertising a Good or a Bad? Evidence from U.S. Magazine Subscriptions. Journal of Business, 77(2): 61-80.

Dukes, A., E. Gal-Or. 2004. Negotiations and Exclusivity Contracts for Advertising. Marketing Science, 22 (2): 222-245.

Ephron, E. 2003. The Paradox of Product Placement. Mimeo. http://www.ephrononmedia. com/article_archive/article_pdf/placement_05_03.pdf

Geweke, J. 1988. Antithetic Acceleration of Monte Carlo Integration in Bayesian Inference, Journal of Econometrics, 38: 73-89.

Goeree, M. S. 2008. Limited Information and Advertising in the US Personal Computer Industry. Econometrica, 76(5): 1017-1074. 
Goettler, R. L., R. Shachar. 2001. Spatial Competition in the Network Television Industry. RAND Journal of Economics, 32 (4): 624-656.

Kaiser, U., J. Wright. 2006. Price Structure in Two-Sided Markets: Evidence from the Magazine Industry. International Journal of Industrial Organization, 24 (1): 1-28.

Liu, Y., D. S. Putler, C. B. Weinberg. 2004. Is Having More Channels Really Better? A Model of Competition among Commercial Television Broadcasters. Marketing Science, 23 (1): 120-133.

Musalem, A., E. T. Bradlow, J. S. Raju. 2007. Who's Got the Coupon: Estimating Consumer Preferences and Coupon Usage from Aggregate Information. Journal of Marketing Research, forthcoming.

Moshkin, N., R. Shachar. 2002. The Asymmetric Information Model of State Dependence. Marketing Science, 21 (4): 435-454.

Nevo, A. 2000. A Practitioner's Guide to Estimation of Random Coefficients Logit Models of Demand. Journal of Economics and Management Strategy, 9, 513-548.

Nevo, A. 2001. Measuring Market Power in the Ready-to-Eat Cereal Industry. Econometrica, 69 (2): 307-342.

Newell, J., C. T. Salmon, S. Chang. 2006. The Hidden History of Product Placement. Journal of Broadcasting \& Electronic Media, 50 (4): 575-594.

Russell, C. A. 2002. Investigating the Effects of Product Placements in Television Shows: the Role of Modality and Plot Connection Congruence on Brand Memory and Attitude. Journal of Consumer Research, 29: 306-318.

Rust, R. T., M. I. Alpert. 1984. An Audience Flow Model of Television Viewing Choice. Marketing Science, 3 (2): 113-124.

Shachar, R., J. W. Emerson. 2000. Cast Demographics, Unobserved Segments, and Heterogeneous Switching Costs in a Television Viewing Choice Model. Marketing Science, 37 (2): 173-186.

Siddarth, S., A. Chattopadhyay. 1998. To Zap or Not to Zap: a Study of the Determinants of Channel Switching during Commercials. Marketing Science, 17 (2): 124-138.

Small, D. S. 2007. "Sensitivity Analysis for Instrumental Variables Regression with Overidentifying Restrictions," Journal of the American Statistical Association, 102 (479), 1049-1058.

Teixeira, T., M. Wedel, R. Pieters. 2008. Moment-to-Moment Optimal Branding in TVCommercials: Preventing Avoidance by Pulsing. Marketing Science, forthcoming.

Van Meurs, L. 1998. Zapp! A Study on Switching Behavior during Commercial Breaks. Journal of Advertising Research, 38 (1): 43-53.

Wilbur, K. C. 2008a. How the Digital Video Recorder Changes Traditional Television Advertising. Journal of Advertising, 38 (1): 143-149.

Wilbur, K. C. 2008b. A Two-Sided, Empirical Model of Television Advertising and Viewing Markets. Marketing Science, 27 (3).

Woltman Elpers, J. L. C. M., M. Wedel, R. G. M. Pieters. 2003. Why do Consumers Stop Viewing Television Commercials? Two Experiments on the Influence of Moment-toMoment Entertainment and Information Value. Journal of Marketing Research, 40 (4): 437-453.

Yang, S., V. Narayan, H. Assael. 2006. Estimating the Interdependence of Television Program Viewership between Spouses: a Bayesian Simultaneous Equations Model. Marketing Science, 3, 336-349. 